OECD Education Policy Perspectives

No. 33

\title{
Teachers' Professional Learning Study: Diagnostic Report for Wales
}

Simon Roy, Philippa Cordingley, Deborah Nusche and Helen Timperley

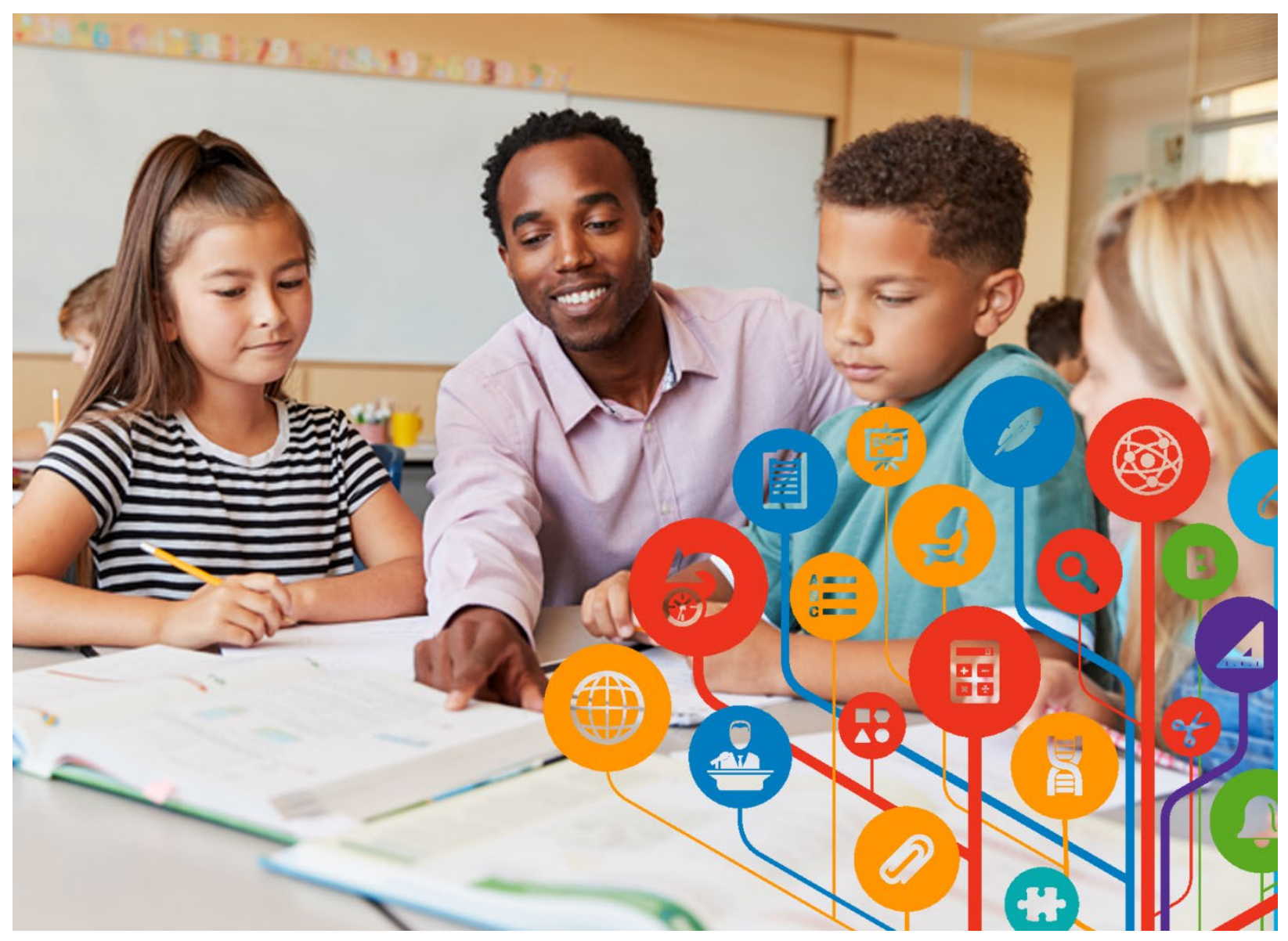




\section{Table of Contents}

\section{Introduction}

The OECD Teachers' Professional Learning (TPL) Study 4

The policy context for the diagnostic study in Wales 6

$\begin{array}{ll}\text { Structure of the report } & 10\end{array}$

2. Creating a system that promotes continuing professional learning 11

National strategy and regulatory frameworks for continuing professional learning 11

Implementing the strategy: resources and actions for professional learning 15

$\begin{array}{ll}\text { Evaluating professional learning at system level } & 19\end{array}$

3. Embedding professional learning in schools 23

School leadership for professional learning and school-level learning culture 23

School-level strategies for structuring and orienting professional learning $\quad 26$

Evaluating and appraising professional learning at school level 29

4. Embedding professional learning in teaching practice 31

Teacher commitment and professionalism 31

Professional learning approaches adopted by teachers $\quad 32$

Evaluative thinking as a basis for continuous improvement 36

$\begin{array}{ll}\text { References } & 39\end{array}$

\section{Figures}

Figure 1.1. The National Approach to Professional Learning

\section{Boxes}

Box 2.1. Professional learning in the Welsh professional standards for teaching and leadership 13 Box 2.2. Use of professional standards to support high-quality professional learning in Australia 14 Box 2.3. Key initiatives for teachers' continuing professional learning in 2020/21 16 Box 3.1. Professional learning days in selected school systems $\quad 28$ Box 4.1. What makes for effective enquiry? Box 4.2. Promoting action enquiry in Victoria, Australia 35 Box 4.3. Linking student formative assessment and teachers' professional learning - an example from the United States 


\section{Teachers' Professional Learning in Wales: OECD Diagnostic Report}

The Welsh Government asked the OECD to undertake a targeted diagnostic study of Wales' system for teachers' Continuing Professional Learning (CPL). Drawing on findings from interviews with Welsh stakeholders and schools, as well as document review, the study team identified strengths and weaknesses of the continuing professional learning system in Wales, as well as opportunities and threats going forward. Key findings from this analysis of strengths, weaknesses, opportunities and threats (SWOT) are summarised in the table below.

\begin{tabular}{|c|c|}
\hline Strengths & Weaknesses \\
\hline $\begin{array}{l}\text { - Teachers' continuing professional learning is at } \\
\text { the heart of a coherent and co-constructed } \\
\text { strategy for schools in Wales, clearly positioned } \\
\text { to support the introduction of the new Curriculum } \\
\text { for Wales and backed by significant public } \\
\text { investment. } \\
\text { School leaders are embracing an enhanced role } \\
\text { in professional learning and peer-to-peer } \\
\text { learning among schools is widespread. } \\
\text { There is strong teacher commitment to } \\
\text { professional learning and improvement, } \\
\text { grounded in renewed professional standards, } \\
\text { which emphasise teacher agency and the } \\
\text { importance of career-long learning. }\end{array}$ & $\begin{array}{l}\text { - The roles and mandates of the different } \\
\text { bodies that form the "middle-tier" of support } \\
\text { for professional learning in Welsh schools } \\
\text { are not always clearly differentiated and } \\
\text { complementary. } \\
\text { - While inter-school cooperation in } \\
\text { professional learning is well developed, it is } \\
\text { reaching its limits in places, while the value } \\
\text { of external expertise for professional } \\
\text { learning is not always recognised among } \\
\text { school leaders and teachers. } \\
\text { There is limited attention to the evaluation } \\
\text { of the effects of professional learning on } \\
\text { teaching practice and pupil outcomes, at } \\
\text { system level, within teacher appraisal and } \\
\text { in the design of professional learning } \\
\text { activities. }\end{array}$ \\
\hline Opportunities & Threats \\
\hline $\begin{array}{l}\text { - The planned shift in evaluation and assessment } \\
\text { arrangements, including the new inspection } \\
\text { regime, creates a conducive environment for } \\
\text { promoting professional learning. } \\
\text { - Schools are receiving increasing support for } \\
\text { enhancing school leadership and school self- } \\
\text { evaluation capacity. } \\
\text { The increased acceptance of digital modes of } \\
\text { cooperation and learning creates opportunities } \\
\text { for expansion of collaborative and innovative } \\
\text { approaches to professional learning, such as } \\
\text { virtual communities of practice, with the potential } \\
\text { to enhance access for practitioners throughout } \\
\text { Wales. }\end{array}$ & $\begin{array}{l}\text { - A lack of clarity about the future of high- } \\
\text { stakes examinations in the new curriculum } \\
\text { risks undermining teachers' focus on } \\
\text { professional learning that supports the full } \\
\text { spectrum of learning outcomes promoted } \\
\text { by the Curriculum for Wales. } \\
\text { Variability in school-level leadership and } \\
\text { evaluation capacity may lead to some } \\
\text { schools being left behind, as Wales' places } \\
\text { increased responsibility on schools and } \\
\text { teachers to shape their own professional } \\
\text { learning journeys. } \\
\text { The economic downturn brought about by } \\
\text { the COVID-19 pandemic may increase } \\
\text { pressure on school funding, including for } \\
\text { professional learning. }\end{array}$ \\
\hline
\end{tabular}




\section{Introduction}

\section{The OECD Teachers' Professional Learning (TPL) Study}

\section{An international study into teachers' professional learning}

Effective teaching is at the heart of a successful education system. There is growing recognition that supporting teachers' professional learning from the beginning to the end of their career is critical to fostering high-quality teaching. The OECD Teachers' Professional Learning (TPL) study examines the policy environments that support teachers' professional growth by exploring common strengths and challenges in participating jurisdictions. In doing so, the TPL study aims to facilitate peer learning, enrich national debates through international exchange and support the development of effective teacher learning systems at both the system and school level.

The study seeks to provide policy makers and practitioners worldwide with evidence and examples of effective and innovative policies to improve initial teacher preparation and teachers' continuing professional learning (CPL). "Teachers' continuing professional learning" is defined in a broad sense including all formal and informal activities aimed at helping teachers to update, develop and broaden their skills, knowledge and expertise. In particular, the TPL study looks at how schools and school systems:

- shape teachers' motivation to engage in CPL;

- ensure that teachers have access to CPL;

- provide different CPL opportunities;

- select and develop CPL content;

- ensure the quality of CPL.

The lens for analysis is provided by the conceptual framework for the TPL study (Boeskens, Nusche and Yurita, 2020[1]). The TPL study seeks to reflect recent advances in the theory and practice of teachers' CPL by considering a broad range of CPL goals to account for teachers' and their pupils' diverse and changing needs; including informal and non-formal settings and formats, such as personal study and collaborative learning and; going beyond the teacher's role as a recipient of CPL to focus on teachers' agency in the learning process, and shifting the emphasis from the individual teacher towards teachers' collective capacity.

The TPL study seeks to avoid a dichotomy between formal professional development (PD) and day-to-day professional learning (PL), which are sometimes treated separately in the literature. Rather, the term CPL is used broadly to include the formal and informal activities that aim to update, develop and broaden the skills, knowledge, expertise and other relevant characteristics of teachers. Traditional professional development courses or seminars are seen as one component within a much larger ecosystem of continuing professional learning opportunities. Professional development initiatives may (or may not) lead to professional learning, but the two terms are not synonymous. From a review of relevant research, the conceptual framework for the study identifies the following characteristics of professional learning, as distinct from professional development: 
- an active role for teachers (individually and collectively) who are considered to be reflective professionals;

- a context-based process that recognises the importance for teachers to be responsive to the particular learning needs of their pupils and for schools to serve the particular needs of their communities;

- a strong evaluative dimension, with teachers systematically examining the effectiveness of their own practice;

- a long-term process that is integrated into regular school life and includes systematically planned opportunities to promote professional growth;

- a process that leads to change in teachers' knowledge bases, beliefs and practice or capacity for practice.

Understanding the broader goals and the context in which CPL systems are operating is essential for analysing their strengths and weaknesses. Countries set different goals and priorities for their CPL systems. While there is an overall consensus that CPL should seek to improve the quality of teaching, the definition and measurement of quality teaching varies across countries. Besides quality teaching, countries often set broader objectives for CPL systems, such as enhancing teacher professionalism and teacher well-being. Countries also differ with respect to the actors involved in setting objectives and in the extent to which stakeholders have a common vision around the goals for teachers' continuing learning.

At the same time, while the goals for school education and for professional learning vary across the OECD, the objective of improving student outcomes is at the heart of all OECD school systems. If valued outcomes for pupils are understood to be the rationale for, and focus of, TPL, then successful professional learning has a positive impact on student outcomes and helps teachers to link particular teaching strategies to their pupils' learning experience. The goal of professional learning is then not just to help teachers to master particular strategies, but to help them develop, implement or adapt strategies based on how their diverse pupils learn and respond to them. It is important to note that across OECD school systems, valued student outcomes typically go beyond academic achievement to include broader learning, holistic socio-emotional development and well-being.

\section{A specific diagnostic analysis for Wales}

This report for Wales forms part of the OECD Teachers' Professional Learning (TPL) study. The analysis is guided by the conceptual framework established for the study (Boeskens, Nusche and Yurita, 2020 ${ }_{[1]}$ ) and, as with other country-specific reports in the TPL study, draws on a combination of desk-based research, diagnostic country visits and comparative analysis. The objective of the OECD diagnostic reports is to provide an international perspective and an independent diagnosis of countries' TPL systems, based on an analysis of each system's strengths, weaknesses, opportunities and threats (SWOT analysis).

In the context of travel restrictions related to the COVID-19 pandemic, the study visit to Wales took place virtually via video-conference from 9 to 19 November 2020, followed by a webinar to share the OECD team's preliminary impressions from the visit on 23 November 2020. The OECD study team comprised Simon Roy (OECD), coordinator of the diagnostic study for Wales, Deborah Nusche (OECD), project lead of the TPL study, Philippa Cordingley (Centre for the Use of Research and Evidence in Education, CUREE) and Helen Timperley (University of Auckland) and Makito Yurita (OECD, seconded from the National Institute for Teachers and Staff Development in Japan). The manuscript benefited from valuable feedback from Louise Stoll (Institute of Education, University College London).

The diagnostic visit was designed by the OECD in collaboration with the Welsh authorities. The purpose of the visit was to collect a broad cross-section of evidence and views on continuing professional learning policy and practice from key stakeholder groups in Wales. This was achieved through structured interviews with government officials and representatives of national and regional agencies, teacher unions, higher education institutions and selected schools. The OECD study team spoke to school management, teachers 
and governors in schools in four schools in four regions of Wales. The schools were selected by the OECD, supported by the national coordinator for Wales, with the aim to maximise diversity in terms of their setting (e.g. urban, suburban and rural), their student body (e.g. size and socio-economic composition) and other characteristics (e.g. type of provider, school performance, educational offer). Each meeting helped the review team to understand the landscape of teachers' professional learning in Wales and the role that different actors play in developing and implementing professional learning policies.

As part of its participation in the study, the Education of the Welsh Government commissioned a country background report (CBR) (Arad Research, 2021 [2]) following the study's conceptual framework and detailed guidelines. Unless otherwise noted, information on the Welsh school system included in this report is drawn from the CBR. The CBR is an important output from the OECD project in its own right, as well as a key source for the study team. The CBR and this report complement each other and should be read in conjunction for a more comprehensive view of the Welsh TPL system.

The OECD study team wishes to extend its gratitude to the many people in Wales who gave time from their busy schedules to inform the study team of their views, experiences and knowledge. The meetings were open and provided a wealth of insights. Special words of appreciation are due to the national co-ordinators in the Welsh Education Directorate, Tanya Wigfall, Lisa Clarke, Joanne Davies and Rachel Hicks. The OECD study team is also grateful to colleagues at the OECD, especially to Cassandra Morley, Daiana Torres Lima and Rachel Linden for administrative, editorial and layout support and to Paulo Santiago for overall guidance.

\section{The policy context for the diagnostic study in Wales}

\section{Significant school reforms with an emphasis on teachers' professional learning}

Teachers' continuing professional learning is at the centre of Welsh education policy. Wales has embarked on an ambitious reform of its school system, centred on a new Curriculum for Wales, designed to deliver a broad and balanced education. The reforms underway seek to create an education system that enables, in the words of the national education strategy, "all children and young people in Wales to become ambitious, capable learners, enterprising, creative contributors, ethical, informed citizens and healthy, confident individuals" (Welsh Government, 2020[3]). Collectively, these outcomes are considered as the "four purposes" of the new Welsh curriculum. As a basis for achieving the vision expressed in the four purposes, every school in Wales will be tasked from autumn 2021 onwards with developing its own new curriculum, based on guidelines set at national level and with support from public agencies, fellow schools and universities.

The emphasis on school responsibility and shared development and implementation of the new curriculum - referred to in policy documents as a process of "co-construction" - reflects a wider shift in thinking about education policy in Wales. In recent decades, the Welsh school system had increasingly adopted a top-down, managerial approach, focused on achievement of a narrowly defined set of national performance metrics at key stages of young peoples' educational pathways (OECD, 2018[4]). The reforms implemented gradually over the last five years seek both to introduce a broader, more nuanced evaluation of school performance and pupil achievement, and to restore greater autonomy to schools and to teachers as professionals. The capacity and skills of teachers and school leaders are crucial factors in allowing this transition to occur and for making the new, more decentralised school ecosystem a success.

Recognising the central role of teachers and school leaders for achieving its goals, the Welsh Government identifies effective professional learning and leadership as key "enabling objectives" to support the introduction of the new curriculum (Welsh Government, 2020[3]). This emphasis is consistent with the Government's focus, informed by previous OECD work, on transforming schools into "learning organisations", in which staff and students learn together to adapt to evolving circumstances and achieve their shared objectives (OECD, 2018[4] ). The Schools as Learning Organisations (SLO) model 
encapsulates the Government's vision of strong, autonomous schools focused on delivering the best possible outcomes for pupils. The model incorporates criteria related to the continuing professional learning of school staff. To further refine its goals for teachers' CPL, the Welsh Government has adopted a specific National Approach to Professional Learning that identifies and links key elements in the support infrastructure for teachers' CPL in Wales (Welsh Government, 2020 ${ }_{[5]}$ ).

Against this backdrop, the Welsh Government asked the OECD to undertake a targeted diagnostic study of Wales' system for teachers' Continuing Professional Learning (CPL). The study complements a broader recent analysis by the OECD on the implementation of the new Curriculum for Wales (OECD, 2020[6]) by taking a closer look at a core aspect of Government policy for schools. The study team set out to identify strengths, weaknesses, opportunities and threats (SWOT) related to: a) the policy environment and support infrastructure for teachers' CPL in Wales, b) the environment for professional learning in schools and c) teachers' engagement with professional learning in their own practice. The body of this report examines teachers' CPL in Wales from these three inter-related perspectives.

\section{Professional learning in Welsh schools reform: key elements}

Before turning to the diagnosis of the current system of teachers' CPL that follows, it is helpful - particularly for readers from outside Wales - to consider in a little more depth four core elements of the Welsh Government's schools reform agenda. These are the principles of the new Curriculum for Wales; the "Schools as Learning Organisations" (SLO) model; the National Approach to Professional Learning and the National Strategy for Educational Research and Enquiry (NSERE).

\section{The Curriculum for Wales - the core of current reforms}

As noted above, the new Curriculum for Wales adopts a holistic approach to defining educational outcomes, with an emphasis on developing capacity to learn, creativity, citizenship and personal development for all pupils aged 3 to 16 in Welsh schools. The objective is to create a more integrated approach to learning, with stronger links and consistency between levels of education and subject areas. To achieve this, the curriculum defines six broad Areas of Learning and Experience (AoLEs) ${ }^{1}$ that bring together existing disciplines, along with three "cross-curricular skills" (literacy, numeracy and digital competency) and four "integral skills" (creativity and innovation, critical thinking and problem-solving, personal effectiveness, planning and organising). For each AoLE, the curriculum framework specifies a number of statements of "what matters" (27 in total), on which all learners will be expected to develop an increasingly sophisticated understanding as they progress through different levels of education. The idea is that learners can identify how their learning at different stages of their education contributes to these ideas and why they are important, thus creating more coherence and continuity.

Curriculum requirements will be set out in legislation (a new Curriculum and Assessment Bill) and guidance has already been published to help schools to design their own curriculum and assessment framework in line with the planned national requirements (Welsh Government, $\left.2020_{[7]}\right)$. The guidance uses "principles of progression" and "descriptions of learning" to set out how learners should progress in relation to each of the statements of "what matters", with expectations expressed for five progression steps. When implemented, the vision is that teachers select content and use their professional skills to support pupils to progress towards and through the broad learning outcomes defined by the curriculum.

The Welsh Government's objective is to introduce the new curriculum for nursery and primary schools and the first year of secondary-school (Year 7) in 2022, expanding to Year 8 in 2023 and an additional school year each year (up to Year 11) in the period to 2026. The aim is for Welsh pupils to sit a reformed version

\footnotetext{
${ }^{1}$ Expressive arts, Health and well-being, Humanities, Languages, literacy and communication, Mathematics and numeracy, Science and technology.
} 
of the GSCEs - national examinations taken by pupils in Year 11 - in 2026. The introduction of the new curriculum creates new requirements for teachers' continuing professional development in Wales. Teachers need to not only to become familiar with the design and structure of the new curriculum framework, but also to have opportunities to hone their skills to be able to develop and implement local curricula within the national framework and to assess pupils' progress against the newly defined learning goals (Sinnema and Stoll, 2020[8]).

\section{Schools as Learning Organisations (SLO) - a model for schools in Wales}

The Schools as Learning Organisations approach was adopted by the Welsh Government to support schools to prepare for the new curriculum in the run up to its launch in 2022. The approach defines the characteristics of schools that are able "to adapt routinely to new environments and circumstances as [their] members, individually and together, learn their way to realising their vision" (OECD, 2018[4]). The approach was co-developed in 2016 and 2017 by representatives of 24 "Pioneer Schools", the four regional school improvement services, the Inspectorate of Education and Training in Wales (Estyn), the National Academy for Educational Leadership, the Education Directorate of the Welsh Government and the OECD.

The SLO model clusters the characteristics of schools that are learning organisation into seven dimensions, each with its own set of descriptors:

1. Developing and sharing a vision that is centred on the learning of all students.

2. Creating and supporting continuing learning opportunities for all staff.

3. Promoting team learning and collaboration among all staff.

4. Establishing a culture of enquiry, innovation and exploration.

5. Embedding systems for collecting and exchanging knowledge and learning.

6. Learning with and from the external environment and larger system.

7. Modelling and growing learning leadership.

As discussed in the diagnosis that follows, the capacity of school staff to learn continuously and innovate to overcome challenges and support pupil learning is at the heart of the SLO model and cuts across the seven dimensions. The extent to which school and teacher practices corresponded to the SLO vision was initially assessed as part of an OECD review completed in 2018 (OECD, 2018[4] ). The SLO survey instrument has since been developed into a national online self-evaluation tool, which the Welsh Government encourages schools to complete annually to gauge their progress in supporting professional learning and developing as a learning organisation (Welsh Government, 2020[9]).

\section{The National Approach to Professional Learning - a key aspect of reforms}

The Welsh Government has articulated a specific National Approach to Professional Learning with the objective of making clear how its different strands of action to support teachers' professional learning relate to the core objective of realising the new curriculum.

As illustrated in Figure 1.1, the National Approach places pupil learning at the centre and views professional learning by teachers and school leaders as crucial to supporting pupils to progress in relation to the four purposes (desired learning outcomes) of the new curriculum. The focus of professional learning is supported and informed by the school context, the work of local authorities and the regional consortia that support schools, and national priorities such as the new curriculum.

The intention is that the school context supports the professional learning of individuals through a framework that practitioners can use to map an "individual professional learning journey" (as part of individual appraisal procedures), by the school-wide Schools as Learning Organisations approach outlined above and by the mix of professional learning approaches adopted in the school. The regional level (primarily the four regional consortia) supports professional learning by providing evidence and guidance 
on improving pedagogy, providing targeted external professional learning opportunities and resources for individual and in-school professional learning and structuring formal accreditation and recognition of professional learning. The national level supports collaborative networks between schools, universities and regional consortia and establishes common professional standards for teachers and school leaders. These aspects are addressed in the relevant sections of the diagnosis:

\section{Figure 1.1. The National Approach to Professional Learning}

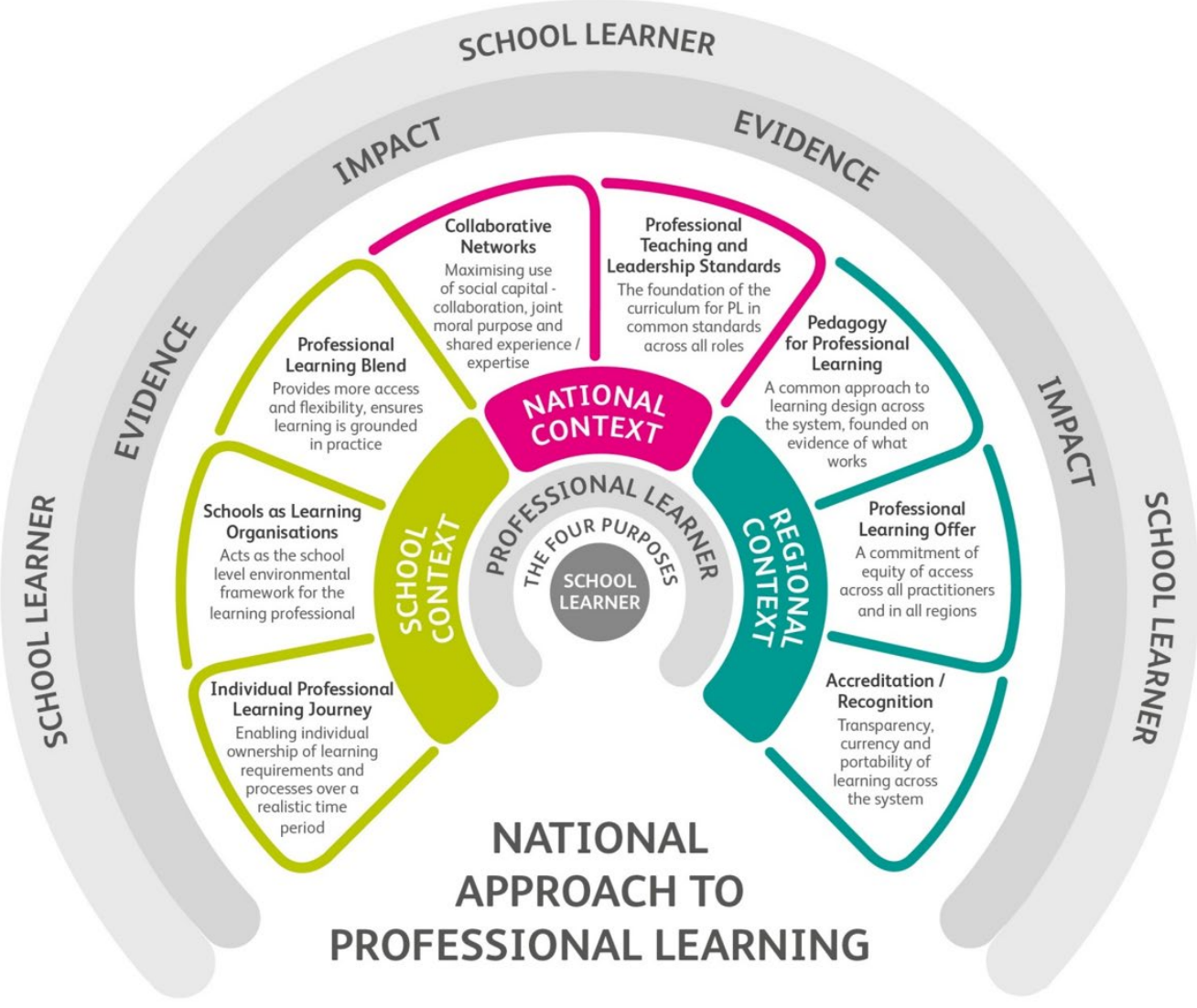

Source: Welsh Government (2020[5] $)$ - National Approach to Professional Learning - High-level summary, https://hwb.gov.wales/professionaldevelopment/national-approach-to-professional-learning (accessed on 13 January 2021).

\section{Research and professional enquiry - a specific focus}

As part of its new National Approach to Professional Learning, the Welsh Government has placed considerable emphasis on promoting professional enquiry among teachers and school leaders as a key mechanism for professional learning. Professional enquiry is understood in Welsh policy as a process of finding out about, or investigating, a particular aspect of professional practice, with a defined rationale and an approach that can be explained or defended (Cardiff Metropolitan University, $2019_{[10]}$ ). By engaging in their own research and enquiry and applying and testing findings in their own classrooms and schools, it is expected that teachers and school leaders can develop their own sense of professional agency and enhance their professional knowledge to support achievement of the outcomes established in the new curriculum (Cardiff Metropolitan University, 2019[10]). 
Starting in 2018, the Welsh Government has funded the National Professional Enquiry Project (NPEP) to develop and test approaches to professional enquiry in Welsh schools. The Project is a partnership between the Welsh Government, the regional consortia that support schools, Welsh higher education institutions and a national network of "Lead Enquiry Schools". Following initial piloting, a first round of enquiry-related work involved partner higher education institutions working with Lead Enquiry Schools and their partner schools in school "clusters" to explore and develop specific aspects of practice relevant to the development and realisation of the new curriculum. In 2020-21, the Project entered a third round of activity, with greater involvement of partner schools alongside the Lead Enquiry Schools and the participation of additional higher education institutions (Hwb, n.d.[11]).

In the latest update of its national strategy, the Welsh Government committed formally to launch a National Strategy for Educational Research and Enquiry (NSERE) (Welsh Government, 2020[3]). This new strategy will further emphasise the importance of enquiry for teachers and learners, seek to ensure better links between educational research across Wales and support a move to a more strategic approach to promoting enquiry and sharing results. The NSERE will focus on developing three core aspects: a) national infrastructure and support for research and enquiry; b) actions to promote a "research-literate" teaching profession and c) building capacity to support enquiry in higher education.

The development of a research-literate profession will involve continuing to scaling-up current "pathfinder" projects undertaken via the National Professional Enquiry Project (NPEP) to involve the whole profession, developing school hubs and establishing enquiry as a key aspect of self-evaluation within the new Evaluation, Accountability and Improvement Framework.

\section{Structure of the report}

The three sections of the report that follow diagnose strengths, weaknesses, opportunities and threats in relation to teachers' continuing professional learning $(C P L)$ in Wales from three angles:

- Section 2 focuses on the national picture, examining the broad framework conditions for teachers' $\mathrm{CPL}$ at national and regional level that influence how professional learning happens in schools. It considers the Welsh Government's overall strategy and policy framework, the public resources allocated to support the professional learning agenda, the roles of the different actors at national level and in the "middle-tier" that support schools and teachers in their professional learning, and the way professional learning and its impact are monitored and evaluated at national level.

- Section 3 considers teachers' CPL from the school perspective, with a particular focus on the leadership of professional learning and school-level conceptualisations, strategies, policies and practices that promote the development of a supportive environment for continuing professional learning in schools. This includes school-level approaches to monitoring the effectiveness of continuing professional learning.

- Finally, Section 4 considers teachers' CPL from a teacher's perspective, drawing on a range of evidence to reflect on the way professional learning is being integrated into teaching practice in Wales. This includes evidence on the experiences of teachers at different stages of their careers in engaging with different forms of continuing professional learning and the ability of practitioners to evaluate the effects of their own learning on pupil outcomes.

This structure reflects an understanding that all actors in the system have their part in creating a culture of professional learning in the Welsh school system. It is national government's responsibility, in partnership with regional consortia and local authorities and other partners, to create conducive framework conditions, the responsibility of school leaders to create conducive environments at school level and the responsibility of teachers to develop themselves as autonomous and collaborative learning professionals.

In line with the brief for this project, this report does not formulate explicit recommendations. Nevertheless, by providing a structured diagnosis from these three perspectives, the report seeks to highlight opportunities to build on progress to date and improve professional learning practice in Wales' schools. 


\section{Creating a system that promotes continuing professional learning}

This section examines the framework conditions that the Welsh Government has put in place in Wales to guide and support teachers' continuing professional learning $(\mathrm{CPL})$ in the nation's school system. This analysis from the system perspective focuses on three key aspects of the national framework:

1. The national strategy and regulatory frameworks that steer approaches to teachers' continuing professional learning in Wales, including the place of professional learning in overall schools policy and professional standards for education practitioners.

2. The financial, human and informational resources mobilised by Welsh authorities to support schools in creating conditions for effective professional learning and practitioners in developing their professional knowledge and skills.

3. The mechanisms in place at national and regional level to support evaluation of the effects of teachers' continuing professional learning.

The system perspective takes a broad view of teacher's CPL in Wales, considering the design of national policy and the national and regional architecture that has been put in place to support teachers' CPL on the ground. The key question is whether the framework conditions and architecture are configured in a way that creates an environment conducive to effective professional learning in schools.

Evidence on the way national policies and support functions play out for schools and practitioners, which may also be relevant for the future refinement of national policies and governance arrangements, is discussed in Sections 3 and 4 of the report.

\section{National strategy and regulatory frameworks for continuing professional learning}

\section{Professional learning is at the heart of a coherent Welsh schools strategy}

Creating a school system where the professional learning of education practitioners consistently drives good student outcomes requires a coherent strategy. Drawing on their work in four high-performing school systems, Jensen et al. (2016[12]) note that professional learning in successful systems reflects a "system-wide strategy" that incorporates reforms in multiple areas of school policy, including resourcing, time use policy, leadership development, and accountability and evaluation.

Over the last four to five years, Wales has placed teachers' professional learning at the heart of its school reforms and made impressive strides towards developing a coherent policy framework to support professional learning in different, and complementary, ways. As discussed in the opening section of this report, at the core of the strategy lies the new Curriculum for Wales, with its emphasis on providing all children in Wales with a well-rounded education, and the model of Schools as Learning Organisations (SLO). The SLO approach situates primary responsibility for ensuring pupils achieve good learning and well-being outcomes with schools and teachers and emphasises that the capacity of education practitioners to learn continuously and respond flexibly to their environment are crucial to student success. 
Realising the new curriculum through developing Schools as Learning Organisations is the overarching goal of the national schools strategy, "Our National Mission" (Welsh Government, 2020[3]). This strategy, initially adopted in 2017 and recently updated, identifies professional learning and leadership as central enabling factors for achieving the national vision. The agenda for professional learning was further articulated in the National Approach to Professional Learning launched in 2018 (Welsh Government, $\left.2020_{[5]}\right)$, which seeks to draw the link between different elements of Government policy that contribute to supporting professional learning in the nation's schools.

The National Mission is supported by a coherent set of specific policy initiatives, which are examined in more detail in the later sections of this report. These include a government-supported partnership between universities and selected schools to promote enquiry-based approaches to professional learning (the National Professional Enquiry Project - NPEP), a National Academy for Educational Leadership (or Leadership Academy) and a new Master's programme in education coordinated between Welsh universities, aimed at practising teachers. The Master's is aimed at teachers in the early years of their career, with those with between three and six years of practice able to apply for a fully funded place. Up to 500 places will be available each year. The National Mission and the policy initiatives that support it are the product of strong political leadership and a high level of commitment to teachers' professional learning within the Welsh Government's Education Directorate. This commitment and focus are exceptional in comparison to many other OECD jurisdictions and provide a strong basis for the enhancement of professional learning in schools.

\section{There is political commitment to a cultural shift that is conducive to professional learning}

In its recent reforms, the Welsh Government has sought to move away from the top-down, managerial approach that had characterised schools policy in recent decades. This is reflected in the approach adopted to developing the new curriculum, which has involved schools and stakeholders across the country in a process of "co-construction". The vision for the new curriculum is that each school will develop its own educational programmes within the national guidelines and that teachers will tailor the content and pedagogical approaches they use to the needs of their pupils (Welsh Government, 2020[7]). The Government has also acknowledged some of the perverse effects of existing school evaluation and accountability requirements, which have focused on standard metrics, including results from standardised pupil assessment, inspections by the national inspectorate (Estyn) and a national system of school "standards groups" (Welsh Government, 2020[13]). The Welsh authorities no longer publish schools standards groups and, as discussed below, are seeking to reform national accountability frameworks to place greater emphasis on school self-evaluation and the support role of the four regional education consortia in school improvement (Welsh Government, 2019 [14]).

The focus on co-construction and gradual move away from centralised metric-based accountability measures is consistent with the vision of schools as autonomous, self-improving learning organisations staffed by capable professionals. It reflects a new commitment to trust schools and practitioners to deliver for their pupils and creates a positive general environment for professionals on the ground.

During the interviews undertaken to prepare this report, the study team was struck by the consistent support for the cultural shift underway in Welsh education at all levels of the system. While acknowledging the challenges of interpreting and implementing the new curriculum, teachers and school leaders welcomed the renewed trust expressed in them by central government. Equally, the regional school improvement agencies, local authorities, universities and stakeholders involved in professional capacity building in schools generally praised the direction of travel taken by the Welsh Government. 


\section{Renewed professional standards define goals for and incentivise professional learning}

As one of the elements in its efforts to promote continuing professional learning in schools, in 2017, the Welsh Government revised the professional standards that define what is expected of - and, in a sense, what it means to be - teachers and school leaders in Wales (Welsh Government, 2019[15]). Co-constructed in consultation with the profession, the new professional standards for teaching and leadership include professional learning as one of the five core standards, alongside pedagogy, collaboration, leadership and innovation. Each standard is divided into elements with descriptors that exemplify how the standards could apply to a teacher's work depending on where that teacher is in terms of their role and career.

For newly qualified teachers (NQTs), the professional standards form a statutory part of their induction process, while serving teachers and school leaders are able to use the standards to guide their career development. The Education Workforce Council (EWC), the independent regulator of the teaching profession in Wales, has developed a Professional Learning Passport (PLP), an online tool that, among other functionalities, allows teachers to record their professional learning experiences against the national standards (EWC, 2020[16] $)$ A similar set of standards has more recently been published for teaching assistants.

The standards for teaching and leadership commit teachers to "continuous engagement in career-long development, collaboration and innovation". As shown in Box 2.1, the highest-level descriptors in the standards for professional learning identify: structured engagement in action research informed by external research, participation in professional networks and a commitment to pupil learning outcomes as key attributes of effective teaching and leadership. These descriptors complement those in the other standards, which also emphasise high quality in pedagogy and openness to new approaches.

\section{Box 2.1. Professional learning in the Welsh professional standards for teaching and leadership}

The four descriptors of "sustained highly effective practice" for professional learning in the Welsh standards for teaching and leadership for teachers are:

1. Wider reading and research findings: "There is structured engagement in an action research community and evidence of practice informed by wider reading and research findings on a national and international scale".

2. Professional networks and communities: "The teacher takes an active role in the wider education community with contributions to journals, conferences or learning communities".

3. Continuing professional learning: "Continuing professional learning is driven by the teacher carefully framing professional growth within the context of the four purposes and a commitment to leading development for colleagues within and beyond the school".

4. Welsh language skills: "The teacher actively seeks opportunities to apply and extend their understanding and skills in the use of the Welsh language".

Source: Welsh Government $\left(2019_{[15]}\right)$, Professional standards for teaching and leadership. Welsh Government, Cardiff, https://hwb.gov.wales/api/storage/19bc948b-8a3f-41e0-944a-7bf2cadf7d18/professional-standards-for-teaching-and-leadershipinteractive-pdf-for-pc.pdf (accessed on 12 February 2021).

Professional standards establish expectations at the system level and can inform individual beliefs about what it means to be a professional educator and approaches to professional learning. The professional standards for teaching and leadership provide a clear articulation of what is expected of teachers and leaders in terms of professional learning. They make clear that professional learning should serve to enhance pupil outcomes, stress the responsibility of individual teachers to engage in professional learning 
throughout their career and place specific emphasis on teacher agency, enquiry, action research and collaboration that, as discussed later, have been shown to be important elements in effective professional learning.

While it is clear that the professional standards have been developed thoughtfully to provide a coherent element in the national system to support teacher professionalism and professional learning, it is less evident how extensively they are used by practitioners and the extent to which they have a direct effect on attitudes and behaviours on the ground. Newly qualified teachers are required to use the standards and the Professional Learning Passport, but some school leaders and teachers consulted during the study expressed scepticism about the practical value of the standards, described in some cases as "abstract". An independent evaluation of the Professional Standards for Teaching and Leadership and the Professional Standards for Assisting Teaching is underway and will report in the summer of 2022. This assessment could be an opportunity to operationalise the standards to a greater extent, potentially by developing and publicising concrete examples of how approaches to professional learning (see Section 4) can contribute to meeting the standards. Box 2.2 provides an example of how professional standards have been used in Australia to guide high-quality professional learning in schools.

\section{Box 2.2. Use of professional standards to support high-quality professional learning in Australia}

Australia has developed the Australian Professional Standards for Teachers, which articulate what teachers are expected to know and be able to do at different stages of their career. Developed by the Australian Institute for Teaching and School Leadership (AITSL), the Standards are a nationally agreed quality assurance mechanism to provide a common understanding and language between teachers, schools, teacher educators and the public across Australia. In Australia, the responsibility for education is shared between the federal government and states/territories. Hence, not all states and territories use the Standards for formal accreditation of teachers' professional learning. However, the Standards are linked to teacher registration requirements throughout Australia, and help teachers engage in professional learning that is aligned with the quality and common criteria elaborated in the Standards.

Australia also invested in exploring approaches to measure teacher impact on student learning and attainment, as well as the use of such measurement tools to improve teacher practice. The University of Melbourne, for example, has investigated key characteristics of effective teachers and teaching as an input to developing policies and systems that support teachers to continually improve their practice and impact. With the aim of promoting excellence in the teaching profession and school leadership, the Australian government funded AITSL to develop and test practical applications of these findings to support teachers to determine their proficiency against the Standards and identify areas for improvement.

AITSL has also developed national policies to support the high-quality professional learning of teachers, including the Australian Charter for the Professional Learning of Teachers and School Leaders (the Charter) and the Australian Teacher Performance and Development Framework (the Framework). The Charter defines the characteristics of high-quality professional learning for teachers; the Framework supports school leaders to develop a positive performance and development culture in their school. The Charter and Framework align to support the development of conditions that enable high-quality professional learning for the improvement of teaching, and the benefit of students. 
AITSL also offers online resources to help teachers engage in high-quality professional learning aligned to both the Standards and teachers' individual needs. These include an online Teacher Self-Assessment Tool with which teachers can review their practice against the Standards and receive personalised feedback. The tool may be used informally for self-reflection, identifying strengths and areas for further development, professional learning planning or to set career goals. It can also be used as part of formal processes, such as performance and development goal-setting, performance reviews and certification at Highly Accomplished and Lead Teacher levels of the Standards.

AITSL has published the 'Improving teacher professional learning' webpage, which includes a suite of resources supporting the central 'High-Quality Professional Learning cycle.' The cycle defines a process through which teachers can identify their learning needs, select and undertake professional learning, apply it in their context, and evaluate its impact. Resources supporting implementation of the cycle include practical guides, video case studies and research reports underpinning the evidence for AITSL's work in the teacher professional learning space. AITSL works in collaboration with states and territories to scope and develop an online community for teachers where teachers can learn from each other by drawing on quality resources.

Sources: Australian Institute for Teaching and School Leadership (2011 $\left.{ }_{[17]}\right)$, Australian Professional Standards for Teachers, AITSL;

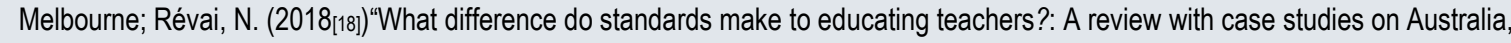
Estonia and Singapore", OECD Education Working Papers, No. 174, OECD Publishing, Paris, https://dx.doi.org/10.1787/f1cb24d5-en; Boeskens, L., D. Nusche and M. Yurita (2020[1]), "Policies to support teachers' continuing professional learning: A conceptual framework and mapping of OECD data", OECD Education Working Papers, No. 235, OECD Publishing, Paris, https://dx.doi.org/10.1787/247b7c4den.

\section{Implementing the strategy: resources and actions for professional learning}

\section{A comprehensive set of policy initiatives is currently backed by significant investment}

To implement the national objectives for professional learning, within the broader reform of the curriculum, the Welsh Government has invested considerable resources into an unusually comprehensive set of support activities. As summarised in Box 2.3, the government has committed over GBP 18 million of public funds in the current academic year to a series of key activities to support continuing professional learning.

The largest single allocation is the Professional Learning Grant (PLG), which is distributed to schools. These funds are intended to be used to pay for releasing and covering staff involved in professional learning and funding school-level posts to support professional learning, including professional learning coaches. The funding is allocated using a formula driven by teacher numbers and, while it is earmarked for professional learning, schools have discretion in how they use the resources available. The GBP 7 million allocated in the current year forms the last tranche of a total of GBP 31 million committed for the three school years 2018-19 to 2020-21. Another GBP 12 million has been allocated for 2021-22. 


\section{Box 2.3. Key initiatives for teachers' continuing professional learning in 2020/21}

In the year 2020/21, the Welsh Government allocated over GBP 18.6 million of public funding to support teachers' professional learning. The key initiatives funded were:

- GBP 7 million allocated directly to schools to enable them to prepare for the new curriculum, forming part of the GBP 31 million investment provided over the three years 2018-2020.

- Approximately GBP 2.465 million allocated to regional consortia and other stakeholders to continue the Curriculum for Wales Development Programme to equip all schools to realise the new curriculum.

- GBP 0.5 million to regional consortia to support self-evaluation in schools.

- GBP 1 million to regional consortia to support teaching assistants.

- GBP 1.1 million to continue to populate the Professional Learning Journey (PLJ) website with resources produced in partnership with regions and schools to provide content for the additional in-service training (INSET) days.

- Approximately GBP 2.6 million to continue the National Professional Enquiry Programme to fund a national network of Lead Enquiry Schools and the seven universities that support them ( $76 \%$ of funding goes to schools, $24 \%$ to universities).

- GBP 0.7 million to universities to develop the new education Master's programme.

- Approximately GBP 1 million (recurrent grant) directly to fund the National Academy for Educational Leadership (Leadership Academy), GBP 0.4 million for the delivery of the Academy Associates programme (for serving head teachers to support), GBP 1 million to fund accredited leadership programmes, and GBP 0.7 million to regions for delivery of the National Professional Qualification for Headship (NPQH).

Note: Information provided by the Welsh Government.

Targeted funding is also provided to the four regional school improvement consortia that work with schools to raise standards and provide a range of support services. This includes specific funding streams to support schools to begin developing their new curricula, to support self-evaluation in schools and to provide dedicated support to teaching assistants.

Other allocations fund a series of specific projects designed to support professional learning at school level, including the National Professional Enquiry Programme (NPEP), the development of a new national Master's programme in education and the National Academy for Educational Leadership (Leadership Academy). As noted in the introduction, the NPEP is a national project designed to develop capacity to engage in enquiry-based professional learning in Welsh schools (see Section 4 for further discussion). It is structured as a partnership between Welsh Government, regional consortia, Welsh higher education institutions (including Aberystwyth University, Bangor University, Cardiff Metropolitan University, Swansea University, University of South Wales (USW), University of Wales Trinity St David (UWTSD), Wrexham/Glyndŵr University,) and a national network of "Lead and Partner Enquiry Schools". The new national Master's programme is being developed by a network of Welsh universities to offer a new professional qualification for practising teachers, while the Leadership Academy supports tailored professional development services for school leaders.

In addition to these direct financial allocations, the Welsh Government has granted schools an additional in-service training day (INSET) each year for 2020-2022, meaning schools have six such days for collective professional development annually. The government estimates that each INSET day costs the equivalent 
of GBP 3.5 million in terms of released teaching capacity. Schools generally have discretion over the activities they organise on INSET days, as well as their timing, although the Welsh Government has asked that the additional (sixth) day is systematically taken in the summer terms during 2020 to 2022.

In 2020, the Welsh Government launched a Professional Learning Journey (PLJ) website, populated with a wide range of resources produced in partnership with regions and schools. The PLJ was designed to support the additional national professional learning INSET day. The PLJ helps to guide schools through the structural and professional learning aspects of preparing for the new curriculum. It explores the different models for professional learning to help schools plan their own "journey". As a starting point, it is recommended that schools take the national Schools as Learning Organisations (SLO) survey to undertake a baseline assessment.

The mix of initiatives to support continuing professional learning in Welsh schools is consistent with the Government's ambition to develop schools as learning organisations and create a wide range of new opportunities for school staff to engage in professional learning. The measures complement recent reforms to the Initial Teacher Education (ITE) system in Wales and help to create a continuum of support for professional learning. This package of activities supports teachers who have completed their initial training, as well as established teachers and teaching assistants, to engage in professional learning, including through developing more advanced enquiry methods, and also offers options for those seeking to advance to leadership roles (notably the national education Master's and the Leadership Academy).

School leaders, teachers and other stakeholders consulted during the study visit welcomed the commitment to professional learning within the policy framework and the funding attached. They nevertheless noted that the level of resources received by individual schools - particularly smaller ones outside the core network of Lead Enquiry Schools - remained modest and had been subject to cuts in the academic year 2020-21 as a result of the COVID-19 pandemic. The Welsh Government reports that the level of resources for the Professional Learning Grant will be restored to its previous level of GBP 12 million in the academic year 2021-22. As discussed in later sections of this report, interviewees also highlighted perceived shortcomings of individual initiatives, even when welcoming the government's overall strategy. Some of those consulted also argued that the large number of activities being developed at the same time could appear overwhelming for schools and teachers.

In the wake of the inevitable economic downturn brought about by the COVID-19 pandemic, a key challenge for policymakers responsible for professional learning in Welsh schools will be to maintain investment, even at rates below those currently seen. Professional learning is an area of activity that is often among the first to be eliminated in any organisation or system in times of financial constraint. Given the centrality of increased school and teacher agency to the Government's school reform agenda, it will be important to make the case that the successful delivery of the new curriculum depends on effective professional learning and the support necessary to allow this.

More generally, the introduction of the new curriculum represents a significant opportunity to transform learning in Welsh schools for both staff and pupils. The changes being enacted, along with the supportive environment, create the space to rethink established practices and to develop and implement new and effective approaches. It is important to build on the momentum generated by the curriculum reform to maintain commitment to and pursue the further development of effective professional learning in Welsh schools.

\section{Regional consortia provide regionally targeted support for learning, but disparities exist}

The four regional consortia are positioned to play an important role in supporting schools to develop their professional learning capacity. In performing this role, the consortia have taken on support functions that historically lay with local authorities. Local authorities remain responsible for a number of statutory areas of professional learning relating to child safeguarding and health and safety. 
School leaders and teachers consulted for the study, as well as representatives of the regional consortia themselves, generally reported that the regional - rather than national - approach in principle reflected a respect for local diversity and different needs in different parts of the country. Tailoring professional learning support to local needs would be consistent with international evidence, which suggests that an appropriate fit between external initiatives and the internal needs of schools is important to ensuring effective support for professional learning (Mintrop and Zumpe, 2019 $[19]$ ). Relatedly, some schools consulted for the study noted that the regional consortia helped to create links with other local schools to support professional learning.

Other school representatives and stakeholders, however, were less convinced that the four regional consortia are able to tailor their professional learning support to the needs of different schools and localities. Wider changes are underway to one of the regional consortia ERW (Ein Rhanbarth ar Waith or Education through Regional Working) in South West Wales. The footprint of the region is changing, with some local authorities withdrawing from regional arrangements and bringing school improvement services back under the direct control of the Local Authority.

There is a clear tension between a desire for locally targeted support for professional learning and the need to ensure efficiency and avoid fragmentation and disparities in the range and quality of professional learning support available to schools across the country. While some interviewees indeed stressed the need for local control, still others argued differences in the approaches taken to supporting professional learning between the four regional consortia already created inequalities in access to good professional learning support between schools in different regions.

The principle of having regional consortia to support professional learning as a driver of school improvement can be seen as a pragmatic compromise. There may well be scope for consortia to review systematically their professional learning support to ensure it responds to the identified needs of the main categories of schools in their regions (whether small primaries, medium-sized middle schools or large secondary schools). At the same time, cross-regional cooperation between the consortia is reported to be increasing and existing links between the bodies appear likely to reduce any damaging inconsistencies in support for professional learning across the nation. The increased acceptance of digital learning modes, including for professional learning resulting from the experience of the COVID-19 pandemic, may also represent an opportunity to engage practitioners from different regions more systematically in joint professional learning activities and reduce barriers to accessing professional learning support, where these exist.

\section{The roles and mandates of "middle-tier" bodies are not always clear}

Ongoing ambiguity about their precise role in the Welsh school system may influence the capacity of regional consortia to support professional learning. Originally, the consortia were established to "challenge" schools whose pupils performed poorly in relation to national standardised assessment and accountability criteria. School liaison officers in some of the consortia are still referred to as "challenge advisers". With the change in national policy direction and the focus on Schools as Learning Organisations, the consortia have been given an enhanced role in supporting - rather than challenging - all schools, including in the area of professional learning. The 2018 OECD review of schools in Wales (OECD, 2018 ${ }_{[4]}$ ) already noted a shift in the balance from challenge to support within consortia, but the interviews conducted for this study suggest this shift is not always clear at school level. Conceptually, challenging practice is an important part of promoting innovation and professional learning. However, such challenge should ideally be the product of internal reflection by practitioners, perhaps supported by external bodies, rather than being something imposed from outside (Fullan, Rincón-Gallardo and Hargreaves, 2015[20]; Farrar, 2015[21]). Creating a system based on trust will be harder if consortia are still associated with the old model of top-down accountability.

Another challenge, arising from the comprehensive nature of the Welsh Government's package of measures to support professional learning is the multiplication of actors and bodies with an explicit role in 
professional learning. The increased number of organisations and actors interacting with schools to promote professional learning is, in principle, positive provided their collective efforts support and are coherent with one another (Bryk et al., 2015[22]). In many cases, such as university involvement in the National Professional Enquiry Programme (NPEP), roles are clear. Nevertheless, the complex ecosystem of support of professional learning in Wales is not always easy for schools and practitioners to navigate. Careful communication is required to ensure target beneficiaries of support are not overwhelmed and that those providing external support are well informed about the aspirations of schools for their staff and their pupils and about the pace of change within them.

A specific issue that did emerge in interviews was the role and capacity of the Leadership Academy. The comparatively new body coordinates initiatives to develop leadership capacity in Welsh schools, including through identifying and endorsing external learning provision and mobilising a network of "Academy Associates" - serving head teachers who are paid to provide peer coaching to leaders and aspiring leaders in the school system. Some interviewees expressed concern that the role of the Leadership Academy was poorly understood in schools and that the small scale of the organisation meant it would not be able to fulfil its mission effectively. Some stakeholders questioned whether the Leadership Academy and the regional consortia sometimes appeared to be acting in competition with each other - albeit in the specialised area of leadership - rather than as part of an integrated system of professional learning support.

Overall, the ongoing reform of the school system is an opportunity to clarify the mandates and inter-relationship of all actors in the middle-tier of the Welsh schools system (the space between central government and schools) and to understand how the reforms re-position relationships with schools themselves. This may be a question of clear communication or, in some cases, refinement of formal mandates. Depending on the future public funding environment, there may also be a need for consolidation of professional learning support structures.

\section{Evaluating professional learning at system level}

\section{Evaluating the effects of professional learning is inherently challenging, although promising approaches exist}

Welsh schools policy emphasises the central role of teachers' professional learning in driving improvements in pupils' learning and well-being. The policies in place, including the vision of Schools as Learning Organisations, encourage teachers to engage in continuing learning as part of their day-to-day practice (through professional standards, for example - see below) and seek to provide teachers with learning opportunities facilitated by others within and outside school.

In a system that is now doing so much to support professional learning, the obvious question is whether these efforts are leading to improvements in leadership and teaching practice and better pupil outcomes - the ultimate goal of all professional learning and the broader curriculum and school reforms underway in Wales. However, evaluating the effects of specific professional learning activities - whether self-directed or externally facilitated on pupil outcomes is inherently difficult. It is challenging because it requires links to be established between: a) professional learning activities; b) what teachers learn from these activities; c) changes made in teaching practice as a result of the learning and; d) changes to relevant pupil outcomes that result from the changes to teaching practice.

Tracing this chain of causality is easiest - but not straightforward - for teachers themselves. They are able to make judgements about what they learned through a particular professional learning activity and how they adapted their practice as a result. They can also observe in real-time, or through well-designed pupil assessments, how their adapted practices influence a range of student outcomes. A capacity for critical self-evaluation of the effects of learning experiences and adjustments to practice is a crucial part of effective continuing professional learning as it allows practitioners to identify strengths in what they are doing and areas for improvement, where further learning is required (Darling-Hammond, Hyler and 
Gardner, 2017[23]; Earl and Timperley, 2015[24]). Building self-evaluation into continuing professional learning processes - both self-directed learning by teachers or facilitated through in-school or external support - requires methodical approaches to evaluating the effects of changes made to practice. Effects will often be mixed and their interpretation involve professional judgements rather than easily quantifiable measures of change.

Obtaining a picture of the effects of professional learning from an external perspective is more challenging still. Schools leaders, organisations that facilitate teachers' professional learning and public authorities who fund professional learning activities are all interested in the effectiveness of the professional learning they support. The international literature acknowledges that external evaluation of individuals' professional learning, whether within schools or for authorities at a higher level, is difficult and available methodologies are contested. In a detailed discussion of evaluation of professional learning, Guskey $\left(2000_{[25]}\right)$ notes that the most basic way to evaluate professional learning, and the most commonly used, is to use participants' reactions or "happiness scales", as they are sometimes called (Sparks, 2004[26]). While participants can reliably assess course inputs, such as the usefulness and clarity of the presentation of ideas and the extent to which materials seemed helpful, this approach to evaluation tells us nothing about the application of learning in practice or the effects of changes in practice on learning outcomes.

The other extreme is to use, as a basis for making external judgements about the effectiveness of professional learning, the kinds of annual standardised assessments of student learning that are applied in Wales and many other OECD jurisdictions. These measures are also increasingly rejected as a measure of teaching effectiveness - and, by extension, the effectiveness of professional learning - because they fail to take into account the complexity of different school contexts. The high-stakes nature of such tests tends to lead to distortions in teaching practice, as focus is placed on the specific requirements of the assessments pupils will take. Moreover, much teachers' professional learning is not specifically targeted on methods to raise pupil performance in standardised outcomes assessments, making pupil performance in such assessments a poor proxy indicator for judging the effectiveness of professional learning.

Once moving beyond these extremes, established approaches to evaluating professional learning programmes and systems remain problematic. Self-reports of acquisition of new knowledge, skills or behaviour changes are notoriously unreliable. Problems include a tendency of "over-assimilation" (Hammerness et al., $2005_{[27]}$ ), where teachers believe they are making significant changes to their practice, but these are too superficial to make a difference to learning outcomes. Equally, individuals who have personal investment in an activity deemed to be socially desirable are unlikely to rate their own behaviour, or extent of behaviour change, negatively. Confidence ratings are also problematic as confidence and competence are very different things. Timperley and Parr $\left(2009_{[28]}\right)$, for example, found no relationship between how confident teachers report they are and observations of the teachers' practice. Some teachers who rated their confidence as very low demonstrated relatively high levels of competence during observation, meaning they were aware of what they did not know. Others rated their confidence as high, but demonstrated more variable levels of competence in practice, indicating they knew less about what they did not know. The phenomenon of more skilled individuals being more aware of the limitations of their own abilities than those with less developed skills is well documented in psychology (Kruger and Dunning, 1999[29]).

Against this backdrop, three related elements do emerge from the international literature as promising approaches to improving evaluation of professional learning:

- The first is to ensure that externally facilitated professional learning activities (i.e. any learning activity that is not purely self-directed) are explicitly designed to help teachers to identify specific goals for how their students' learning experiences and outcomes will change if their professional learning is successful (Cordingley et al., 2015[30]). 
- The second is to ensure that professional learning facilitators, coaches and mentors, as well as middle-tier and government bodies involved in professional learning - the people supporting teachers and school leaders in their professional learning - are equipped with skills to guide and undertake evaluations of the professional learning they are facilitating.

- The third is to focus explicitly on supporting teachers (professional learners) to develop "evaluative thinking" and the skills to undertake critical self-evaluation of the effects of their own professional learning and relate this to the wider goals of their school and the school system (Earl and Timperley, 2015[24]).

\section{Wales has not always designed its professional learning policy interventions with evaluation in mind}

As highlighted above, Wales supports teachers' continuing professional learning through targeted activities facilitated, in particular, by the four regional consortia, the National Professional Enquiry Project (NPEP) and the Leadership Academy. Many of those interviewed for this study indicated they think evaluation of these support actions is challenging in the short to medium term, not only because of the methodological difficulties, but also because the interventions in question have not been designed with an explicit mapping - or intervention logic - that links professional learning activities undertaken through to pupil progress.

Interviews with policymakers and stakeholders suggest that many specific professional learning support activities often focus exclusively on intermediate goals - such as teachers' career progression or teachers' skills development - rather than explicitly tracing the link between the intermediates goals and pupil outcomes. Making this link explicit in all professional learning support activities would be consistent with the National Approach to Profession Learning (see Figure 1.1), which places pupils at the centre of its strategy. The study team found little evidence of requirements or guidance that encourages those supporting professional learning to ensure relationship between professional learning activities and the ultimate goals of the education system is made systematically.

A further complication for evaluating professional learning programmes is that professional learning support bodies interpret their coordination, brokerage and accountability roles in different ways. Ensuring clarity in the objectives and mandates of different support bodies, as highlighted above, and clear intervention logics mapping actions to intended effects is an important requirement for being able to evaluate the effectiveness of professional learning activities supported.

\section{The planned shift in evaluation and assessment arrangements is positive for professional learning}

Looking more broadly, several changes underway in system-wide school evaluation and assessment frameworks in Wales appear likely to create an environment conducive to effective teachers' professional learning.

Over recent decades, the Welsh school system came to rely increasingly on standardised assessments to judge pupils' learning outcomes and embedded the results of such assessments in its school accountability mechanisms through publishing school results and using outcomes data to direct school-level interventions from the regional consortia and Estyn. More recently, many in Wales have been concerned that these established accountability mechanisms might encourage schools and teachers to behave in ways that are counter-productive for achieving good outcomes for all pupils (Welsh Government, 2019[14]). For example, a narrow focus on attainment at certain threshold levels - such as grade "C" at GCSE - incentivised practitioners to focus on maximising the numbers of pupils attaining these levels, potentially at the expense of those performing above or substantially below the thresholds. From the perspective of professional learning, narrowly defined assessment and accountability criteria may have incentivised teachers' and schools to focus on acquiring the skills and capacity needed to get pupils to meet these criteria, rather than those needed to help all children to achieve their potential. 
To address these challenges and develop a system that provides a more rounded assessment of pupil performance in relation to the new curriculum, the Welsh Government plans a fundamental review of the national evaluation and improvement (accountability) mechanisms. In line with the Schools as Learning Organisations approach that guides policy, the Draft Evaluation and Improvement Arrangements published by the Welsh Government (Welsh Government, $2019_{[14]}$ ) place emphasis on structured self-evaluation as a basis for self-improvement by schools. Such self-evaluation would become the core of a revised school inspection regime, run by Estyn. The Government is also exploring how measures of child well-being can be incorporated in a future, more broad-based and nuanced, national system of school accountability. Officials noted that a balanced scorecard approach could be an option for system-level reporting, while highlighting the need to proceed with care to avoid just having a "longer checklist' that might encourage tick-box benchmarking.

\section{High-stakes examinations continue to influence teachers' attitudes to professional learning}

While the general trend in Wales is clearly towards lower emphasis on such standardised testing, questions remain unanswered about the future form of the high-stakes system at GCSE examinations at the end of Key Stage 4. In Wales, as in England and Northern Ireland, these exams are an important stepping-stone in young people's educational pathway, with their results at GCSE having a significant influence on their further study options in academic or vocational tracks. The high-stakes nature of the exams for pupils - as well as their traditional prominence in secondary-school accountability mechanisms - means their content has a strong influence on teaching content and practice in secondary schools - and thus on teachers' priorities for professional learning.

A review of the content and form of GCSEs in Wales is underway, with the intention of launching the new examinations for pupils starting Year 10 in 2025. However, proposals have not been published at the time of writing and many teachers, school leaders and stakeholders interviewed for this study expressed concern that ongoing uncertainty about the new exams made it challenging to focus professional learning efforts for teachers responsible for teaching "GCSE years" (Years 10 and 11). Providing a clearer vision of how the four purposes of the Curriculum for Wales will translate into new external examinations for 16-year-olds will help to overcome this current threat to well-focused professional learning in secondary schools. 


\section{Embedding professional learning in schools}

This section considers how schools in Wales are embedding continuing professional learning into their leadership approaches, school development strategies and the internal organisation of their work. The key question is the extent to which schools are translating the Welsh Government's vision for professional learning into practice, as part of their wider efforts to become "learning organisations". The discussion of strengths, weaknesses, threats and opportunities focuses on three aspects of the school-level environment for professional learning:

1. the understandings of professional learning among school leadership and the development of school-level learning cultures;

2. different school-level strategies for structuring and orienting continuing professional learning for teachers and for further developing leadership capacity for professional learning in schools and;

3. the mechanisms used at school level to evaluate the effectiveness of professional learning, including as part of school self-evaluation and staff performance management.

The analysis below recognises that school leadership teams have a central responsibility in promoting a culture of continuing professional learning in their schools. The success of the Curriculum for Wales depends on the ability of schools and their staff to create their own curricula to achieve the four purposes for all pupils. This, in turn, depends on the ability of school leaders to orient and focus learning in their schools, to refine their own skills and to support staff in pursuing learning activities that respond to pupil needs.

The National Approach to Professional Learning and the different policy initiatives that support it emphasise the development of strong school leadership, supported, notably, by the Leadership Academy. They also stress collaboration in professional learning within and between schools and the importance of increasing capacity for critical self-evaluation in schools to identify professional learning needs and evaluate the effects of professional learning activities undertaken.

\section{School leadership for professional learning and school-level learning culture}

\section{School leaders recognise the importance of professional learning for new curriculum}

There is a growing culture of professional learning in Welsh schools. School leaders, teachers and other stakeholders who closely observe developments in schools in Wales consistently highlighted the progress made in increasing emphasis on professional learning at school level in recent years. At the same time, it was freely acknowledged that understanding of, and commitment to, continuing professional learning varies between schools. Schools that have been most closely involved in Welsh Government policy development in recent years - as "Pioneer Schools" in developing the Schools as Learning Organisations framework and now as "Lead Enquiry Schools" - are likely to be among the most advanced in their thinking 
and most committed to the professional learning agenda. However, the strong communication and programme of actions by the Welsh Government and regional consortia discussed in the previous section, as well as widespread development inter-school cooperation, appear likely to have promoted a wider focus on professional learning across the school system.

The Welsh Government's focus on continuing professional learning is widely welcomed by school leaders and the teaching profession generally. The schools consulted for the study, selected primarily based on geographical and size criteria, all happened to have had leadership roles within the system and had used this to develop a range of staff roles for championing professional learning. All schools were grasping the opportunities created by the current school reform process with energy and thoughtfulness to make significant changes to their approaches to professional learning.

Discussions with schools, other stakeholders and the abundant school-level case studies recorded as part of the SLO process (Welsh Government, 2018[31]) reveal many examples of activities to translate the national vision into action. This is enabling school leaders and teachers to explore and deploy professional learning to implement system reforms and school improvement in ways suited to their local contexts. All schools consulted in the study emphasised they take a "whole-of-staff" approach to professional learning, creating learning opportunities for those in leadership, teaching and support roles.

School leaders consulted during the study recognised that continuing professional learning is part of a continuum proceeding from Initial Teacher Education (ITE), through induction and support for early career teachers to ongoing professional learning linked to school development work. The way that the new Curriculum for Wales, the Schools as Learning Organisations approach, the professional standards and other parts of the reform agenda are now embedded into ITE was seen as positive. Equipped with a strong knowledge of the reform goals, school leaders are encouraging newly qualified teachers to help to spread awareness of the importance of professional learning.

\section{Many school leaders are embracing their enhanced role in promoting professional learning}

International evidence consistently points to the importance of school leadership in creating a culture and frameworks conducive to effective teachers' continuing professional learning (Elmore, $2004_{[32]}$ ). Within the Welsh Government's vision for schools, school leaders have a special responsibility for driving efforts to make their schools into learning organisations capable of implementing the new curriculum. Several aspects of the broader policy framework for continuing professional learning allow school leaders to assume greater responsibility and develop greater capacity for steering learning in their schools. Development of leadership skills is embedded as an integral part of the system-wide vision for a professional learning continuum and leadership is a component of the professional standards for teaching assistants and teachers, as well as school leaders. As such, school leaders are positioned as leaders of learning and all educators are encouraged to develop leadership capacity.

The enhanced emphasis on leaders and teachers as professional learners and the development of their capacity to lead and model professional learning through enhanced agency is not restricted to the abstract and theoretical. It is also seen in examples of a significant shift in practice through, for example, teachers and leaders recognising the value incollaboration, coaching, and enquiry as effective means of professional learning: something those consulted for this study saw as a significant and relatively recent change. Leaders and teachers were able to report valuable experiences of contributing to intra-school and inter-school collaboration, as well as working with middle-tier and other external actors with confidence about and pride in their contributions.

Many school leaders and teachers consulted cited design of the new curriculum and the development of new approaches to reflect national reform as being a central part of their approaches to professional learning. Colleagues with leadership roles at several levels in schools reported that they contribute to the broader system reform process through involvement in activities organised by middle-tier or system-level 
bodies and were both proud of this contribution and aware they had learned through the process. They also reported that they had developed a range of within-school professional learning support roles through, for example, in-school teaching and learning teams or school improvement projects. Such roles encompassed championing professional learning itself, diagnosing starting points through self-evaluation and promoting culture change through professional learning.

There was evidence of extensive personal engagement and commitment to professional learning and collaboration both within and outside of formal structures, including an emerging acknowledgement of the importance of coaching and mentoring and enquiry. The study team was particularly impressed by the number of teachers and leaders who thought a significant element of their professional learning activity was part of their professional identity: something to be pursued within and beyond their school life.

\section{Understandings of core principles of good professional learning are not yet embedded}

Understandably, given the scale of recent change, not all aspects of the policy vision for effective continuing professional learning appear to be embedded in understandings and practice at school level. In different schools, different aspects of national policy seem to be a key focus or more of a background consideration. The study team encountered many examples of in-house innovation in schools, with variations in the way professional learning is conceptualised and operationalised. The evidence gathered for this study suggests three characteristics of effective professional learning, highlighted in Wales' national policy frameworks, are not universally acknowledged in schools and not systematically reflected in current school strategies for professional learning.

The first issue is one of framing. Ideally, strategies for professional learning, whether at school or individual level, should work back from learning and development needs identified among pupils (Timperley et al., $2007_{[33]}$ ). Once such needs are identified, practitioners and school leaders can work to identify the knowledge and skills teachers need to implement modified practices to address these needs. It seemed to the visit team that discussion of professional learning in Wales, like in many other systems, is more typically framed in terms of the learning needs of practitioners or the need to respond to external changes, like the new curriculum, rather than the identified learning needs of pupils. There sometimes appears to be a tendency to see supporting teachers to prepare the new Curriculum for Wales as an end in itself, rather than to see effective realisation of the curriculum as a means to enhancing pupil outcomes.

The second issue relates to understanding the value of different inputs to support professional learning and embedding this understanding in school-level strategy. The Welsh Government has sought to encourage schools and practitioners to make professional learning a collaborative effort, drawing on input from peers within the school and from other schools, support from regional consortia and academic specialists (particularly in the area of enquiry). Although schools consulted for the study were generally positive about intra- and inter-school collaboration, interviewees were sometimes more sceptical about the value and role of input from specialists not working in a school environment. This attitude risks narrowing the range of input for professional development and weakening attempts to develop a culture of professional enquiry (Timperley, Kaser and Halbert, 2014[34]; Hammerness et al., $2005_{[27]}$ ). Also schools (and those supporting them) that did recognise the value of specialist contributions tended to focus on pedagogy and to underplay the contribution of content specialists to challenging established practices and assumptions, illustrating excellence and supporting sequencing in curriculum design and evaluation.

The third issue, already discussed in the introduction, is the limited emphasis placed in schools on evaluation of the effects of professional learning on pupils and on the importance of debriefing and sharing of findings after experiments with new practices. School leaders noted challenges in evaluating professional learning and typically saw it as a summative assessment challenge - in other words, an expectation that the effects of professional learning will eventually show up in pupil assessment results. Although summative assessments can be an important part of judging the effectiveness of teaching and the application of professional learning, continuous evaluation of teaching strategies and pupil responses 
and progress should be an integral part of the professional learning process. School leaders - and teachers - appear to be finding it hard to draw the golden thread between professional learning, changes in practice and pupil responses to changes in teaching.

Increasing conceptual clarity regarding all three of these areas could help harness the evident enthusiasm about the opportunities offered by the new curriculum in schools and bring greater precision to planning for high-quality professional learning in ways that enhance teachers' collective efficacy (Donohoo, 2016 [35]). Embedding the understandings and approaches highlighted above into school strategy represents a major effort and is something that has been achieved in few OECD school systems. The particularly comprehensive policy and support framework in place in Wales nevertheless stands the system in good stead to achieve this.

\section{Support for building leadership capacity exists, although its reach is not yet clear}

Implementing effective approaches to developing professional learning in schools is challenging and an area where school leaders may need support. The need to invest in the skills and capacity of school leaders more generally is well recognised in Wales and there have been steps to support capacity development. These include the establishment of the National Academy of Educational Leadership (Leadership Academy), integrating Schools as Learning Organisations model into leadership development programmes and support for leadership from middle-tier agencies. The national Curriculum for Wales Programme launched by regional consortia in 2020, initially focused on supporting senior and middle leaders to realise the new curriculum. The programme will be made available to all practitioners from autumn 2021.

School leaders and stakeholders consulted for the study acknowledged that the Leadership Academy is a welcome symbol of a structural commitment to building leadership capacity for Welsh schools, but almost all argued that its potential has yet to be realised. Moreover, interviewees often questioned the reach of Leadership Academy activities, noting its comparatively small budget and the limits to its network of Academy Associates. Such doubts might reflect the fact the Leadership Academy is a relatively recent creation and the body's activities have not yet been felt across the school system. They could also reflect the real limits of the organisation and the fact there is some confusion about the respective roles of the Leadership Academy and regional consortia. It will therefore be important to evaluate the results achieved by the Leadership Academy in the next one to two years, to ensure its strategy and functioning are adequately aligned with school leadership needs in Wales.

\section{School-level strategies for structuring and orienting professional learning}

\section{Some, schools are implementing coherent school-level professional learning policies, but approaches appear to vary across the system}

Just as the conceptualisation of the end goals of professional learning varies between schools in Wales, so do the practical approaches to structuring and organising professional learning activities. The evidence collected from stakeholder groups and schools consulted for this study suggests that schools are at different stages of developing comprehensive professional learning strategies and embedding these into their day-to-day activities. All schools encountered in the study research displayed a commitment to continuous professional learning for staff. However, while some support staff engagement in professional learning on a primarily ad hoc basis for individual staff members, others are taking steps to implement more coherent, school-wide approaches to professional learning, with differentiation in the support offered to teachers at different stages of their career.

The school visits offered anecdotal evidence on the range of professional learning opportunities offered to teachers in Welsh schools. Some schools noted that nearly all professional learning undertaken by their staff is explicitly linked to strategic design and development activities, such as work to prepare aspects of 
the new curriculum. In these cases, school leaders and senior teachers identify and encourage specific staff members to take up opportunities at departmental or school level as they arose. One school reported that they relied on activities facilitated by external partners as the primary means to support continuous professional learning for their staff. At least one other school adopted a more systematic and proactive approach for all staff, starting with an assessment of staff learning needs. On this basis, opportunities are identified, with structured learning support informed by work by an established non-profit educational support organisation for new and more junior staff and promoting more self-directed collaborative learning approaches based on enquiry for more experienced colleagues. For the work involving enquiry, the school worked in partnership with the regional consortium and the local university.

There are strengths in all of these approaches to continuing professional learning and ways of focusing and supporting it. Going further, all could benefit from understanding in a more structured way the benefits and weaknesses of the full range and of the particular approaches being used. For example, the schools organising professional learning around the school development activities would benefit from developing more structured approaches to enquiry to ensure that the teachers and leaders have a chance to engage critically and in depth with what they are learning. The schools offering the very structured programme of facilitator-led support could benefit from moving forward to enable teachers and leaders to develop metacognitive control over what they are learning and starting to introduce structured enquiry processes. This would enable the school to take advantage of new freedoms and to explore the different ways in which what is fundamentally a pedagogically driven programme can be enhanced to contribute to the cross-disciplinary demands of the new curriculum.

\section{Peer-to-peer learning between schools is becoming widespread, but not without challenges}

Collaboration and peer-to-peer learning between schools can be a source of motivation and information for an individual school's improvement, provided this collaboration has a shared focused on pupil outcomes and the participants relate to one another in ways that promote changes in thinking and practice. Evidence suggests that for school cooperation to be effective, each school needs to be able to take something from the collaboration, evidence of progress towards desired outcomes needs to be carefully monitored and participants need to both trust and challenge each other (Fullan, Rincón-Gallardo and Hargreaves, 2015[20]).

Alongside in-house professional learning strategies, the study team noted strong appreciation in schools of the value of school-to-school collaboration for enhancing professional learning and expanding leadership capacity. Collaboration across the primary and secondary levels of education and partnership development was reported to have helped to construct shared understandings around the issues that are common across school levels. There were also growing signs that inter-school collaboration, such as collaboration between departments across several schools as part of professional learning focused on school improvement. This too appears to be contributing to the development of shared understanding about issues and pedagogy within schools.

Some collaboration between schools is embedded in activities to support system reform, such as the network of Lead Enquiry Schools (formerly Pioneer Schools) and their clusters of partner schools. In the schools consulted for the study, such collaboration has been a catalyst for increased school-to-school professional learning. Collaboration with other schools complements in-school support, mentoring and coaching activities, including for newly qualified teachers. External school-based collaboration was generally viewed by those consulted as contributing to school improvement in schools with an active role in developing professional development policies and programmes. Such collaboration has the potential to build school-up momentum for reforms, particularly if it is captured and codified.

The study team also observed the engagement of teachers and school leaders in professional learning communities and platforms which have the potential to support the exchange of knowledge of effective teaching practice, including that developed through enquiry. An example is the "Talk Pedagogy, Think 
Learning" online community to discuss and share pedagogical practice (Welsh Government, n.d.[36]). Such networks can help to share knowledge, once the principles and an infrastructure for capturing and sharing evidence emerging from practice and enquiry-oriented learning has been put in place.

The tendency to draw school leaders into national and regional work away from school, including inter-school cooperation and mentoring, brings with it the risk that the leaders in question are overloaded and diverted from developing professional learning in their own schools. Although few interviewees consulted during the study highlighted this as a major challenge, it is an important consideration in planning future inter-school cooperation.

\section{Additional resources for INSET days are welcome, although some of the time released could perhaps be used more flexibly}

As noted in the introduction, schools in Wales have six in-service training (INSET) days a year, which can be used to organise school-wide professional learning activities. This includes an additional day a year for the period 2020-2022. The staff time released for INSET days constitutes a significant investment by the Welsh Government and is used for multiple purposes. For example, the INSET days provide an opportunity for all staff to receive coordinated briefings and training on aspects of national policy and to discuss and contribute to school development plans in a collective setting. The additional INSET day has been specifically funded to support the introduction of the new curriculum, recognising the scale of change being undertaken and the need for coordinated preparation, discussion and information sharing within schools.

"Whole-school" days for professional learning have the potential to be highly effective ways to create space to engage in professional learning and can be used to organise a variety of learning activities that complement self-directed and other forms of professional learning undertaken by school staff at other times. As illustrated in Box 3.1, jurisdictions in several OECD countries have introduced system-wide professional learning days, similar to the INSET days in Wales, albeit with specific characteristics.

\section{Box 3.1. Professional learning days in selected school systems}

Professional learning days for teachers and school leaders that are agreed or mandated at system level have been introduced in several OECD jurisdictions, although approaches vary between systems.

- In New Zealand, "Teacher-Only Days" (TODs) or "Call-back days" for professional learning have historically been organised during school holidays. However, the latest collective agreement between the central government and the main teaching unions creates eight additional teacher-only days spread over the three years 2020 to 2022 to support the implementation of changes to national secondary-school examinations (NCEA), as well as wider strengthening of curriculum, progress and achievement practice. The dates of the days are fixed in the collective agreement and materials and guidelines are developed and distributed nationally.

- In Canada, the negotiated number of professional development days in Canada range from 20 days per school year in Quebec to three days in Newfoundland and in Saskatchewan. In Quebec, Manitoba, and Nova Scotia, some of these centrally-mandated days can also be used by teachers for self-directed professional learning. The provision of funding for self-directed learning days in other provinces typically depends on individual school board policies that make allowances for one or two individually directed learning days per teacher per year.

- In the Australian state of Victoria, each teacher is entitled to one "Professional Practice Day" (PPD) per term (four days per year), when they are released from their scheduled duties to focus on the improved delivery of high-quality teaching and learning. These days are in addition to the four existing "pupil-free days" per year, organised as "whole-school" activities in line with guidelines from the state government. 
Teachers must use their PPDs on professional learning activities that are consistent with statewide priorities and the School Strategic Plan (SSP) in their school. Supporting resources for teachers and for school leaders in planning PPDs have been developed by the Victorian Department of Education.

Sources: New Zealand Government (2020[37]), Accord Teacher-Only Days, Ministry of Education, https://www.education.govt.nz/school/school-terms-and-holiday-dates/accord-teacher-only-days/ (accessed on 15 April 2021); Campbell, C. et al. (2017[38]), The State of Educators' Professional Learning in Canada, Learning Forward, Oxford, OH; Victoria State Government (2020[39]),Professional practice days, Victoria State Government - Education and Training, https://www.education.vic.gov.au/school/teachers/teachingresources/practice/improve/Pages/ppe-practice-days.aspx (accessed on 15 April 2021).

In investing in professional learning days, governments need to consider the different purposes for which the time released will be used and how centrally organised "whole-school" days might fit into the broader professional learning strategies pursued by schools and teachers to achieve maximum effectiveness.

In terms of purpose, it is useful to distinguish between time spent on briefings, activities and discussions that can helpfully be organised through school-wide events during INSET days and the time that teachers in different fields and roles need to pursue their own professional learning to support good outcomes for their pupils. A key question is how much time should be invested in these two types of activity. In the example from Victoria (Australia) in Box 3.1, the government has made a distinction between "Pupil-free Days", which are similar to traditional, all-school INSET days in Wales and "Professional Practice Days", which teachers can use more flexibly through the year to pursue their own professional learning. In planning future investments in time released from teaching, it may be instructive for the Welsh Government to examine the experiences gained in Victoria from implementing this approach.

The second issue is how to achieve the sustained, cumulative and quality professional learning that authors such as Darling-Hammond et al. (2017 $\left.{ }_{[23]}\right)$ advocate as a basis for effective teaching (Cordingley et al., $\left.2015_{[30]}\right)$. Despite the advantages of "whole-school" events such as INSET, work by Bodkin et al (2013[40]), in Ontario highlights that the workshop-style activities often used in all-staff training days succeed in raising awareness, but do not guarantee transfer and assimilation of the ideas shared without time, follow-up and coaching support. Ideally, professional learning focused on enhancing teaching practice should involve iterative combinations of exploration of students' learning needs and experiences, new ideas from research and best practice and professional dialogue rooted in analysing evidence from teachers' experiments with those ideas and approaches in classrooms (Cordingley et al., 2015 $5_{[30]}$ ). Sequences of this kind can be powerful because they enable teachers to experiment, and refine their approaches in the light of insights from students' responses and feedback on that from specialists and colleagues.

As preparations for the new curriculum in Wales progress, there is scope to review more systematically how INSET days are used in Welsh schools and how activities undertaken during this time can be linked effectively to teachers' broader professional learning journeys.

\section{Evaluating and appraising professional learning at school level}

\section{Schools are developing capacity for self-evaluation, but may need to increase capacity to identify staff learning needs and evaluate the effects of professional learning}

The study team noted that capacity for structured self-evaluation within schools is growing. In particular, this is driven by the Schools as Learning Organisations (SLO) survey, which allows schools to evaluate themselves against criteria covering the seven dimensions of the SLO framework. A significant proportion of Welsh schools complete this survey annually. This experience will support the more general shift to 
greater reliance of self-evaluation by schools, planned in the new national accountability framework and Estyn inspection regime (Welsh Government, 2019[14]). Noting that self-evaluation has historically been weak in Welsh schools, Estyn is currently developing a "National Evaluation and Improvement Resource" to bring consistency to school-level self-evaluation across Wales (Estyn, 2020[41]).

However, welcome as this more systematic approach to school self-evaluation might be, the discussions with schools held as part of this study suggest schools might benefit from further support in accurately identifying professional learning needs for all staff and in supporting staff to evaluate their own learning needs prior to and during professional learning activities. Although there is evidence of increasingly systematic approaches in schools to identifying the professional learning needs of staff and proposing learning options, this sometimes appears to been as a "one-off" diagnosis, rather than a continuous process, and recognition of the need for systematic assessment of professional learning needs is not universal. Furthermore, the need to enhance capacity to evaluate the effects of professional learning, highlighted in Section 1, extends to school level. As noted elsewhere in this report, although evaluating the effects of professional learning is challenging, careful design of learning activities, the involvement of capable facilitators and a focus on building the evaluation capacity of staff can all help in creating a culture of evaluation and focus on effectiveness (Cordingley et al., 2015[30]).

Evaluation of the effects of professional learning is important for individual teachers and groups of teachers engaged in individual or collective learning. It is important for those facilitating professional learning because the evidence it generates from pupils helps them accurately to refine the support they offer to teachers. It also allows school leaders to judge the relevance and effectiveness of the different professional learning activities they support and helps those involved in supporting professional learning in the middle-tier agencies and in universities to understand whether different initiatives have the desired effects. Such evaluation is also important for the quality of findings from enquiry-based learning and knowledge that can be shared across the system.

\section{Existing experiences of evaluating professional learning offer learning opportunities}

Despite a limited focus on evaluation of the quality and effects of continuing professional learning, there are already pockets of innovation which offer further potential for developing evaluation of professional learning. The study team noted, for example, that a group of teachers in one school consulted reported using an increasingly holistic approach to evaluating the effects of professional learning though qualitative observation of changes in learners and learner behaviours, alongside quantitative evaluation of learning outcomes.

Moreover, there is a growing emphasis on research and evaluation generally at regional level. The National Professional Enquiry Project and planned Master's in Education Practice are also intended to increase evaluation capacity. In some school interviews the study team noted evidence of in-depth evaluation within professional learning processes and activity. At least one university already designs a focus on impacts for pupils into the professional learning support they offer, although they acknowledge this is not widespread. Greater standardisation and structure in ITE processes has also made the power of formative evaluation more visible. The COVID-19 pandemic, with the resulting cancellation of external examinations and reduction in external inspection activities, has accelerated the already initiated shift in the evaluation and improvement environment and empowered school leaders. This is also thought by national stakeholders to have the potential to accelerate the development of a broader research and evaluation climate as part of professional learning. 


\section{Embedding professional learning in teaching practice}

This section examines evidence collected by the study on teachers' attitudes to and practical engagement with professional learning. The diagnosis here draws on interviews with teachers themselves, reports by school leaders and other stakeholders consulted during the study and selected documentary evidence. The comparatively limited availability of information on teachers' practices and perceptions of professional learning in Wales means that the findings here are often based on reported patterns and trends rather than any more systematic forms of evidence. Nevertheless, findings presented reflect consensus views among stakeholders consulted for the study and can inform further reflections and discussions in Wales.

As with the previous sections, this section is structured into three parts:

1. First, consideration of the teachers' commitment to professional learning and the place of professional learning in teachers' understanding of their own professionalism.

2. Second, the different approaches to professional learning adopted by teachers.

3. Third, the capacity of teachers to engage in evaluation of their own learning.

Wales' National Mission for education and the Schools as Learning Organisations approach emphasise the role of increased teacher agency in helping to achieve the four purposes of the new Curriculum for Wales and driving continuing professional learning. The Professional Standards for Teaching and Leadership stress professional learning as a core part of teachers' professional identity and there is an aspiration for all teachers to identify their "Individual Professional Learning Journeys" as part of the National Approach to Professional Learning. The "Professional Learning Passport" (PLP), an online tool developed by the Education Workforce Council (EWC), allows teachers to record their professional learning experiences against the national standards (EWC, 2020[16]).

\section{Teacher commitment and professionalism}

\section{A growing sense of professional agency among teachers}

As in the case of school leaders, the study team found evidence of a cultural shift underway for teachers, which was helping them to become agents of change. In particular, the team heard from teachers who were demonstrating a transition from being passive recipients of continuing professional development to being active agents in driving their own and each other's professional learning. The teachers the team spoke to welcomed the trust they saw being offered to the teaching profession and generally understood that with increased agency comes responsibility for self and collegial improvement through professional learning. Teachers interviewed valued the opportunity to participate in ongoing school and curriculum development activities as a context for continuing professional learning, which, in turn, helped to generate an enhanced sense of belonging to a recognised profession. This was reflected in the teachers' pride in how they were responding to the Covid-19 pandemic. 
For any learner, whether a student or professional, taking agency and responsibility for their learning increases motivation and engagement by increasing self-determination (Deci et al., 1991 [42]). Bandura $\left(1989_{[43]}\right)$ defined agency as, "the capacity to exercise control over one's own thought processes, motivation, and action". When learners exercise agency, they are "proactively engaging in their own development and can make things happen by their actions" (Johnson, Pajares and Usher, 2007, p. 105[44]).

It is desirable for teachers to experience professional agency in their own learning environments. However, professional agency is not the same as professional autonomy, which is sometimes interpreted to confer full freedom to choose individually the professional learning in which to engage or, indeed, whether to engage at all. Such a conceptualisation of full individual "autonomy" is inconsistent with the vision of schools as learning organisations promoted by Welsh policy, which emphasises both pupil needs and developing a collaborative learning culture as drivers of individual professional learning. For professional learning to result in improved outcomes for all pupils, it must be the learning needs of pupils, such as development of the four core purposes of the Curriculum for Wales, that shapes what their teachers learn (Timperley et al., 2007[33]). This student focus will inevitably place the most important constraint on individual autonomy. The requirement to situate individual professional learning within a collective schoolwide learning effort also creates an additional - and valuable - counterweight to absolute interpretations of professional autonomy.

The focus on collaborative and collective learning in the Schools as Learning Organisations model is based on evidence from an extensive body of international literature that supports the premise that learning collaboratively with one's colleagues has greater impact than learning individually (Kaser and Halbert, 2017[45]; Stoll et al., 2017 [46]; Cordingley et al., 2020[47]). Collaborative professional learning is particularly effective when teachers focus on how pupils are responding to the changes made in teaching practice and challenge each other about their teaching and the effects observed (Cordingley et al., 2015[30]; Cordingley et al., 2020[47] $)$. Effective professional learning environments support teachers in developing agency to make a difference for their pupils, within a collaborative approach that draws a coherent line between pupil, teacher, school and system learning (Timperley and Parr, 2009 $\left.{ }_{[48]}\right)$.

The limited amount of evidence available to this study does not lend itself to drawing firm conclusions about teacher agency in Wales. However, the discussions with teachers, school leaders and other stakeholders revealed differing understandings of the distinction between agency and autonomy among teachers. In particular, while far from universal, some teachers had difficulty in articulating how professional learning activities they engaged in linked to student outcomes or the wider learning objectives of their school. This varying understanding among teachers was also witnessed among school leaders, professional learning support staff in regional consortia and academics involved in enquiry projects with schools.

Developing a coherent new understanding of professional agency and what this means for approaches to professional learning across a profession is challenging and inevitably takes time. It is the impression of the study team that Wales' teachers and schools have made considerable progress in this regard. However, it will be important to ensure the notion of agency is carefully communicated in policy and professional learning activities.

\section{Professional learning approaches adopted by teachers}

\section{Teachers are beginning to engage in enquiry-based approaches, but more rigour is needed}

The earlier sections of this report have acknowledged the impressive journey Wales has made in reconceptualising its approach to professional learning. The Schools as Learning Organisations model and the National Approach to Professional Learning emphasise the agency of teachers as learners in school learning communities and mark a decisive shift away from the idea that professional learning is just about 
going on courses. In this context, encouraging teachers to use professional enquiry-based methods to develop their teaching practice has been a priority for the Welsh authorities. Professional enquiry - inspired by enquiry-based learning for pupils - is a form of professional learning in which professional learners start by investigating what is going on for their pupils and formulating hypotheses about how their practice may be impacting on the situation for these pupils. On this basis, they can then research and experiment ways to test the hypotheses they have developed. Enquiry is widely accepted as an effective form of learning (for practitioners and pupils) as it is a form of professional learning that exploits individuals' own agency (Timperley, Kaser and Halbert, 2014[34] ).

The Welsh Government has provided ongoing financial support for the National Professional Enquiry Project (NPEP) with its network of Lead Enquiry Schools. Engaging with enquiry represents a significant shift in practice for established teachers in Wales, as enquiry has not historically been emphasised in Initial Teacher Education in the country. Many of the teachers encountered by the study team in Wales spoke primarily about non-enquiry-based approaches when asked to provide examples of their recent engagement in professional learning. However, the study team heard about a growing and commendable emphasis on enquiry-oriented professional learning in some of the schools visited and about the positive engagement of teachers with NPEP from the NPEP team.

Reports on the results of NPEP highlight that enquiry activities undertaken in the scope of the project most frequently focused on planning for and implementing locally-based curriculum and particular pedagogical approaches. Teachers were supported in their enquiry activities through face-to-face engagement sessions and online contacts between the university partners and participating schools. The most recent "results report" notes that participating staff had been enthused and engaged by the work, with the quality and standard of the research process appearing to have improved (NPEP, 2019 $9_{[49]}$ ). However, the report also notes teachers' unfamiliarity with the curriculum, associated subject-specific vocabulary, pedagogies and the enquiry process in general, as well as challenges with internal collaborative planning and collaboration across schools (Sinnema and Stoll, 2020[8]). These challenges would appear consistent with the impression gained by the study team that enquiry is not yet embedded into the developing cultures of professional learning at the level of schools and individual practitioners, an impression consistent with the findings of the recent OECD review of curriculum reform in Wales (OECD, 2020[6]).

What is noticeably absent from both the reports of the results of the NPEP project and teachers' accounts of their engagement with enquiry during the study interviews is a focus on linking enquiry-informed practice to pupil learning and outcomes. In particular, the study team found little reference to pupil progress in general or techniques to capture and measure the effects of amended teaching practice on pupil outcomes in particular.

For enquiry to have an impact on teaching and pupil outcomes, a number of conditions need to be met. As summarised in Box 4.1, research by Jensen et al $\left(2016_{[12]}\right)$ and Timperley, Kaser and Halbert, (2014[34]) shows that effective enquiry requires a clear focus on enhancing student learning and well-being through investigation of identified challenges, is collaborative, draws on external expertise, and is highly evaluative. These conditions appear currently to be only partially met in much enquiry practice in Welsh schools. However, as discussed in the remainder of this chapter, there are emerging foundations on which to build. 


\section{Box 4.1. What makes for effective enquiry?}

Based on analysis of systems that have been successful in improving student learning outcomes, recent research identifies a series of features of effective enquiry:

- Student learning and well-being are clearly understood as the reason to engage in the enquiry process and as the basis for monitoring progress and the success of the enquiry. This learning focus is contextualised for subjects, learning challenges and specific groups of learners.

- The enquiry teams engage in causal reasoning by constantly asking "What is contributing to particular student outcomes?" and "Why is this situation happening?"

- Enquiry is collaborative, with the teachers enquiring into similar student learning problems and experiences as a means of taking collective responsibility for pupil progress and well-being.

- Those engaged in enquiry are supported by trained facilitators and school leaders and relevant resources that provide clear structured guidance that help teachers navigate inevitable complexity and help them:

- To manage the practical, intellectual and emotional demands of professional learning within the enquiry process;

- Challenge orthodoxies to develop new ways of approaching the situation;

- Evaluate the enquiry experiences and student responses in ways that secure depth of impact.

- Enquiry processes are highly evaluative with evidence collected formatively throughout to assess impact on students and refine next steps.

- Enquiry processes develop relevant professional knowledge, deepen and become more challenging through iterative spirals, through which teachers test approaches, observe results and amend their approaches in light of what they observe.

- Enquiry process are given adequate time to develop initial hypotheses, find relevant evidence, test approaches and evaluate results.

Sources: Based on Timperley, H., L. Kaser and J. Halbert (2014[34]), "A Framework for transforming learning in schools : innovation and the spiral of inquiry", Seminar series, No. 234, Centre for Strategic Education; Jensen, B. et al. (2016 $[12])$, Beyond PD: Teacher Professional Learning in High-Performing Systems, National Center on Education and the Economy,, https://www.ncee.org/wpcontent/uploads/2015/08/BeyondPDWeb.pdf (accessed on 12 February 2021).

While most of the principles underpinning effective enquiry are implicit in the policies and initiatives used in Wales, these principles could be articulated more explicitly. This would make it possible to assess the elements of different professional learning approaches more coherently. For example:

- To what extent is teachers' engagement motivated by their awareness of gaps in their current knowledge and skills needed to address student-related learning challenges?

- Is the learning serving to deepen their professional knowledge and their understanding of underpinning principles?

- Are teachers continuously using evidence to check the effects of their new professional practice and are they noticing and responding to what really matters?

- Is their engagement helping them to become aware of biases that may be getting in the way of addressing specific student-related learning issues?

One of the recommendations of the most recent activity report of the NPEP project (NPEP, 2019[49]) is to provide more guidance materials to support teachers to engage in professional enquiry. Such materials might indeed help to maximise the potential of the enquiry processes to impact on professional learning, 
teaching practice and student outcomes. The Victorian Department of Education and Training (Australia) has adopted enquiry as a primary mode of promoting professional learning (Victoria State Government, $\left.2020_{[50]}\right)$ and has developed a suite of such resources to guide the practice of schools and regional staff who support the schools. These resources include a conceptual overview of where the enquiry process fits in the Departments' professional learning support, particularly in its positioning in professional learning communities, and may serve as a useful guide for similar developments in Wales (see Box 4.2).

\section{Box 4.2. Promoting action enquiry in Victoria, Australia}

The Framework for Improving Student Outcomes (FISO) is an enquiry-based approach. The resources developed by the Victorian government identify and unpack four strategic enablers to support implementation of enquiry including:

1. Self-evaluation capability throughout a school

2. Real-time data for monitoring implementation

3. Leadership capability for school improvement

4. Robust implementation structures.

Other resources include a detailed four-stage maturity matrix that integrates the enquiry process into the professional learning communities. The four stages are articulated for each of: Vision, values and culture; Building professional learning communities; Use of data; Structures and systems; Building practice excellence; Curriculum planning and assessment; Empowering students and building school pride.

In addition, schools are supported by designated positions in government agencies, with Department of Education staff appointed at the regional level, who are tasked with supporting people in these positions and their school-based enquiry teams. The regional staff are similarly supported with their own professional development in leading the enquiry process.

Source: Victoria State Government (2020[50]), Implementing FISO through professional learning communities, https://www.education.vic.gov.au/school/teachers/management/improvement/plc/Pages/plcguide.aspx (accessed on 18 February 2021).

\section{There is a growing culture of collaborative learning among teachers}

The study team saw evidence of a practice shift underway in the sense that teachers recognise and celebrate the value in collaboration and coaching as effective means of professional learning. This was evident in the extent to which teachers are taking leadership roles through both intra-school and inter-school collaboration, as well as working with middle-tier and other external actors. The study team was particularly impressed by the thoughtful, detailed and in-depth accounts of a group of teachers who were working very carefully on interdisciplinary curriculum development, while remaining wary of diluting depth of content knowledge. More generally, the examples of professional learning given by teachers, school leaders and external stakeholders testify to a growing culture of collaborative learning within and between schools that is positive for the future development of the school system. However, while there was widespread awareness of the value of collaboration, there was little awareness of how to mobilise and systematise this to focus professional learning activities on achieving specific aspirations for pupils.

\section{The value of external expertise is not always recognised by teachers}

The evidence on good enquiry highlighted above points to the important contribution of specialist external expertise to effective continuing professional learning. External experts help to ensure that deep-seated 
orthodoxies in teaching practice can be challenged, explain state of the art approaches, help to develop practical theories about the effects of professional learning and enable in-depth formative evaluation (Cordingley et al., 2015[30]). In Wales, NPEP, in particular, is designed to bring such expertise into schools, while the new national Master's in Education is intended to build advanced pedagogical capacity in the incumbent teaching workforce. However, the study team did not find much evidence of an awareness among teachers of the value of such external contributions.

It may well be that schools, rather than individuals, need to develop a collective sense of ownership of specialist and research-based knowledge at a time when schools are building a critical mass of confidence. This might arise, for example, through the creation of a peer-reviewed archive of practitioner-generated enquiry results and conclusions to develop bottom-up momentum that complements the contribution of higher education institutions. This would also help to build capacity among practitioners to codify and share knowledge generated through enquiry-based practices, a challenge highlighted in Section 3.

Teachers and school leaders acquire different types of knowledge that may be either generalisable or apply to the particular context of their community, school and students. Codifying knowledge about teaching processes that are likely to be successful across multiple contexts is key for schools to retain, share and build on this knowledge base, even when staff transitions occur. As causal research designs are costly and time-intensive and require specific knowledge and skills, an intermediate level of evidence may be to collect insights across multiple teachers on the effectiveness of a particular strategy. Such a process of external knowledge development, that would include both cross school and research practice partnerships, is a critical part of developing the knowledge base in teaching (OECD, 2019 ${ }_{[51]}$ ).

\section{Evaluative thinking as a basis for continuous improvement}

\section{Wales' shift towards more self-evaluation in schools creates space for professional learning, but requires capacity building among practitioners}

As noted in Section 2, Wales is planning to move its national system of school evaluation towards a model based on structured self-evaluation, albeit maintaining some system-wide accountability mechanisms. Such a move is consistent with the findings of international literature on school evaluation and accountability (OECD, 2013[52]). This evidence suggests that accountability systems based on "internal accountability" are likely to be more powerful than compliance-oriented evaluation systems at promoting school improvement. This is because they encourage teachers and schools to take ownership of school improvement and exercise agency to make such improvement happen, including through professional learning. However, while such systems create more space for teachers and school leaders to direct professional learning to serve the needs of their schools and pupils, they also require greater evaluative capacity from teachers and school leaders, which creates a requirement for professional learning. The study team encountered a widespread recognition of the need to build a more generalised culture of self-evaluation among teachers and school leaders. By extension, this would include self-evaluation by teachers of their existing professional competencies and related needs for professional learning and, ultimately, evaluation of the professional learning they engage in. Notwithstanding the challenges, a robust culture of evaluation of professional learning among teachers could feed into more comprehensive evaluation of professional learning initiatives and strategy at system level (see Section 2).

The existing Schools as Learning Organisations (SLO) survey, which schools are invited to complete annually, is designed to create a culture of reflective self-evaluation and provide external observers with a general system-level overview of the extent to which schools are engaging with relevant aspects of professional learning. The Professional Standards also offer an element to support the evaluation of professional learning because, as one government official interviewed for this study put it, "they shape how we want teachers to be reflecting and also feed into performance management". This builds the potential for a coherent and developmental approach to tracking the links between professional learning and professional growth. 
Moreover, the planned reform of the school inspection regime implemented by Estyn also holds the potential to both incentivise and evaluate professional learning in schools. Estyn has not traditionally focused on professional learning in its inspection framework. However, as the agency prepares to shift to a new framework with greater focus on self-evaluation and more regular visits for all schools (rather than just those with identified weaknesses), there is scope to situate schools' professional learning policy and practice firmly within the remit of inspectors.

There are many challenges in shifting a system from a primarily external evaluative one to one of primarily internal accountabilities. One of the main issues is developing capacity. Fullan et al. (2015[20]) argue that any attempt to reset evaluation and accountability structures must begin by building the professional capital of teachers and leaders. By this they mean, "the collective capacity of the professional and its responsibility for continuous improvement and for the success of all students". Both Farrar (2015[21]) and Greany $\left(2015_{[53]}\right)$ additionally argue that leadership capability is essential to the evaluation and accountability setting inherent in a self-improving system.

\section{Professional standards are not yet used to their full potential in performance management}

The professional standards for leadership, teaching and assisting in education, discussed in Section 2, provide a valuable definition of the professional learning attitudes and behaviours expected of practitioners in Wales. They are intended to set clear expectations about effective practice during a practitioner's career, enable practitioners to reflect on their practice, individually and collectively, against nationally agreed standards of effective practice and "affirm and celebrate their successes" and support practitioners to identify areas for further professional development. Importantly, they are also conceived as a reference for performance management (Welsh Government, 2019 ${ }_{[15]}$ ).

The study team noted variable understanding among school leaders and teachers of the role of performance management in linking school and individual professional learning needs and aspirations and in monitoring the effectiveness of professional learning undertaken by individual staff members. The fact that performance management has not yet been reviewed to ensure that arrangements reflect system reforms and goals also inhibits progress. In particular, more support and guidance may be required to ensure that teachers' development goals are identified through performance management, analysed cumulatively and used to prioritise areas for professional learning and relevant professional learning activities in School Development Plans. The Welsh Government has commissioned an evaluation of how the professional standards are being used. This evaluation is an opportunity to assess how the standards can be used more effectively in performance management to further the professional learning agenda.

\section{The "system" in Wales could do more to promote teachers' capacity to evaluate the effects of their professional learning}

Teachers need to be able to evaluate the effects of the professional learning activities in which they engage. As highlighted above, a capacity for critical evaluation of the effects of teaching practice on pupils is a crucial component of effective enquiry-based professional learning. Constantly monitoring the adequacy of student progress and the impact of teaching is fundamental to developing an evaluative mind-set. This involves using evidence to identify what is working well and what needs to change, with particular attention paid to the impact on those students currently not well served by Welsh schools. Evaluative thinking applies the key principles of student formative assessment to teaching programmes and the learning processes involved in making them more effective. Box 4.3 provides an example.

Using evidence in this way also requires the development of skills to identify relevant evidence, as well as collecting, analysing and interpreting it in ways that can be used to inform ongoing decision-making (Earl and Timperley, 2015[24]; Jensen et al., 2016[12]; Schildkamp, 2019 $9_{[54]}$. This means starting any professional learning processes with evidence of what is currently happening for student learners using both qualitative 
and quantitative evidence, then to have this evidence form the reason to engage in new professional learning. Also needed throughout is evidence of the changes made by teacher in their practice and evidence of the resulting outcomes for students on an ongoing basis (Ell et al., 2020[55]).

\section{Box 4.3. Linking student formative assessment and teachers' professional learning - an example} from the United States

If teachers' professional learning is focused on developing students' mathematical thinking, for example, then the starting point might be to work with the teachers to develop a profile of students' current ways to think mathematically. A study by Kazemi and Franke $\left(2004_{[56]}\right)$ in a United States in an elementary school involving multiple grade levels focused on this issue. The process began with the research facilitators and teachers developing a multi-grade common mathematics problem that was analysed for the qualities of mathematical thinking prior to teachers using it with their students. The teachers then presented the problem to the students and collated samples of students' responses and the strategies they used.

Initially, the teachers were able to collate how successfully the students solved the problem, but experienced difficulties with eliciting students' thinking and the strategies they used because they had never asked the students to explain their thinking prior to the professional development. As a result, they were unable to record the students' thinking. These records were kept as a baseline against which to assess both teacher and student progress. The research facilitators worked with the teachers to observe the students' strategies in more detail and together recorded instances of teachers reporting when they were able to elicit students' thinking and to evaluate the quality of that thinking. As a result of recording instances of students' thinking and strategies, teachers were able to evaluate the progress both they were making in eliciting the students' responses and the sophistication of the students' articulation of their strategies. The teachers came to realise that many of the assumptions they were making about the strategies the students used were misguided and the assistance they gave to the students mismatched to the problem.

Source: Kazemi, E. and M. Franke (2004[56]), "Teacher Learning in Mathematics: Using Student Work to Promote Collective Inquiry", Journal of Mathematics Teacher Education, Vol. 7/3, pp. 203-235, http://dx.doi.org/10.1023/b:jmte.0000033084.26326.19.

Moreover, the self-evaluations at school level, that also feed into system-wide evaluation mechanisms, rely on the capacity of teachers to evaluate their own practice and the professional learning in which they are engaged. Research evidence (Darling-Hammond, Hyler and Gardner, 2017[23]; Timperley et al., 2007[33]; Cordingley et al., 2019 [57]; Cordingley et al., 2020[47] $)$ suggests that it is important to design continuing professional learning activities and support by working back from a clear understanding of how student progress and well-being will be improved if professional learning for teachers is successful. In this context, evaluation techniques that allow practitioners to observe marginal gains to identify if changes in practice and students' responses are moving in the right direction and to use the resulting evidence to fine tune professional learning activities and support, are particularly important. The study team found little evidence of teachers and schools focusing on student outcomes as the starting point for professional learning activities and only occasional examples of this being explicitly built into support programmes. The team also noted in its review of policy documents and discussions with teachers, school leaders and stakeholders a general lack of focus in policy and support actions on developing evaluation skills to allow teachers to explore and understand the relationship between what they do on pupil outcomes. This represents a clear area of opportunity for improvement. As highlighted throughout the report, the comprehensive policy framework and shared commitment across stakeholders in the Welsh school system provide excellent conditions for moving ahead. 


\section{References}

Arad Research (2021), Teachers' Professional Learning: Country Background Report for Wales for the OECD TPL Study, https://www.oecd.org/education/teachers-professional-learning-study/.

Australia Institute for Teaching and School Leadership (2011), Australian Professional Standards for Teachers, https://www.aitsl.edu.au/docs/default-source/national-policy-framework/australianprofessional-standards-for-teachers.pdf (accessed on 16 February 2021).

Bandura, A. (1989), "Human Agency in Social Cognitive Theory", American Psychologist, Vol. 44/9, pp. 1175-1184, http://dx.doi.org/10.1037/0003-066X.44.9.1175.

Bodkin, B., K. Broad and S. Molitor (2013), A Synthesis of Reports on Professional Learning and Professional Community Facilitated by the Elementary Teachers' Federation of Ontario., Ontario Institute for Studies in Education, Toronto.

Boeskens, L., D. Nusche and M. Yurita (2020), “Policies to support teachers' continuing professional learning: A conceptual framework and mapping of OECD data", OECD Education Working Papers, No. 235, OECD Publishing, Paris, https://dx.doi.org/10.1787/247b7c4d-en.

Bryk, A. et al. (2015), Learning to Improve: How America's Schools Can Get Better at Getting Better, Harvard Education Press, Cambridge, MA, https://eric.ed.gov/?id=ED568744 (accessed on 17 February 2021).

Campbell, C. et al. (2017), The State of Educators' Professional Learning in Canada, Learning Forward, Oxford, $\mathrm{OH}$.

Cardiff Metropolitan University (2019), Undertaking professional enquiry: an introduction for lead enquirers, Cardiff Metropolitan University, Cardiff, https://hwb.gov.wales/api/storage/aeb2810d-f6704718-87a1-299696ce5156/guide-to-undertaking-professional-enquiry.pdf (accessed on 25 January 2021).

Cordingley, P. et al. (2019), Constructing Teachers' Professional Identities, Education International, https://issuu.com/educationinternational/docs/2019 ei research constructing teach (accessed on 11 February 2021).

Cordingley, P. et al. (2015), Developing Great Teaching Lessons from the international reviews into effective professional development, Teacher Development Trust, https://tdtrust.org/wpcontent/uploads/2015/10/DGT-Full-report.pdf (accessed on 24 February 2021).

Cordingley, P. et al. (2020), Developing Great Leadership of CPDL.

Darling-Hammond, L., M. Hyler and M. Gardner (2017), Effective Teacher Professional Development, Learning Policy Institute, Palo Alto.

Deci, E. et al. (1991), "Motivation and Education: The Self-Determination Perspective", Educational Psychologist, Vol. 26/3-4, pp. 325-346, http://dx.doi.org/10.1080/00461520.1991.9653137.

Donohoo, J. (2016), Collective Efficacy, How Educators' Beliefs Impact Student Learning, Sage Publishing, Thousand Oaks, CA.

Earl, L. and H. Timperley (2015), "Evaluative thinking for successful educational innovation”, OECD Education Working Papers, No. 122, OECD Publishing, Paris, https://dx.doi.org/10.1787/5jrxtk1jtdwfen.

Ell, F. et al. (2020), Leading Professional Learning: Practical strategies for impact in schools, ACER Press, Melbourne. 
Elmore, R. (2004), School Reform from the Inside Out: Policy, Practice, and Performance, Harvard Education Press, Cambridge, MA, https://eric.ed.gov/?id=ED568807 (accessed on 25 February 2021).

Estyn (2020), A national evaluation and improvement resource for schools | Estyn, Estyn website, https://www.estyn.gov.wales/supporting-education-reform/national-evaluation-and-improvementresource-schools (accessed on 13 February 2021).

EWC (2020), Professional Learning Passport, Education Workforce Council, https://www.ewc.wales/site/index.php/en/professional-development/professional-learning-passport (accessed on 12 February 2021).

Farrar, M. (2015), "Learning together: The power of cluster-based school improvement", Centre for Strategic Education Seminar Series Papers, No. 249, Centre for Strategic Education, http://www.cse.edu.au. (accessed on 11 February 2021).

Fullan, M., S. Rincón-Gallardo and A. Hargreaves (2015), "Professional capital as accountability", Education Policy Analysis Archives, Vol. 23/0, p. 15, http://dx.doi.org/10.14507/epaa.v23.1998.

Greany, T. (2015), "More fragmented, and yet more networked: Analysing the responses of two local authorities in England to the Coalition's 'self-improving school-led system' reforms", London Review of Education, Vol. 13/2, pp. 125-143, http://dx.doi.org/10.18546/LRE.13.2.11.

Guskey, T. (2000), Evaluating Professional Development, Corwin Press, Thousand Oaks, CA.

Hammerness, K. et al. (2005), "How Teachers Learn and Develop", in Darling-Hammond, L. and J. Bransford (eds.), Preparing Teachers for a Changing World: What Teachers Should Learn and Be Able to Do, Jossey-Bass, San Francisco, CA.

Hwb (n.d.), National professional enquiry project - Hwb, Hwb website, https://hwb.gov.wales/professionaldevelopment/national-professional-enquiry-project (accessed on 13 April 2021).

Jensen, B. et al. (2016), Beyond PD: Teacher Professional Learning in High-Performing Systems, National Center on Education and the Economy, , https://www.ncee.org/wpcontent/uploads/2015/08/BeyondPDWeb.pdf (accessed on 12 February 2021).

Johnson, M., F. Pajares and E. Usher (2007), "Sources of Writing Self-Efficacy Beliefs of Elementary, Middle, and High School Students", Research in the Teaching of English, Vol. 42/1.

Kaser, L. and J. Halbert (2017), "Teachers leading reform through inquiry learning networks", in Teachers Leading Educational Reform, Routledge, http://dx.doi.org/10.4324/9781315630724-4.

Kazemi, E. and M. Franke (2004), "Teacher Learning in Mathematics: Using Student Work to Promote Collective Inquiry", Journal of Mathematics Teacher Education, Vol. 7/3, pp. 203-235, http://dx.doi.org/10.1023/b:jmte.0000033084.26326.19.

Kruger, J. and D. Dunning (1999), "Unskilled and unaware of it: How difficulties in recognizing one's own incompetence lead to inflated self-assessments", Journal of Personality and Social Psychology, Vol. 77/6, pp. 1121-1134, http://dx.doi.org/10.1037/0022-3514.77.6.1121.

Mintrop, R. and E. Zumpe (2019), "Solving real-life problems of practice and education leaders' school improvement mind-set”, American Journal of Education, Vol. 125/3, pp. 295-344, http://dx.doi.org/10.1086/702733.

New Zealand Government (2020), Accord Teacher-Only Days, Ministry of Education, https://www.education.govt.nz/school/school-terms-and-holiday-dates/accord-teacher-only-days/ (accessed on 15 April 2021). 
NPEP (2019), Welsh Government Professional Learning Enquiries Research Project Quarterly report Cycle 2: Summary, National Professional Enquiry Project, Cardiff, https://hwb.gov.wales/api/storage/fc3146ab-8efe-4e86-b716-82041d7e71ef/npep-cycle-2-summaryreport-en.pdf (accessed on 18 February 2021).

OECD (2020), Achieving the New Curriculum for Wales, Implementing Education Policies, OECD Publishing, Paris, https://dx.doi.org/10.1787/4b483953-en.

OECD (2019), Working and Learning Together: Rethinking Human Resource Policies for Schools, OECD Reviews of School Resources, OECD Publishing, Paris, https://dx.doi.org/10.1787/b7aaf050-en.

OECD (2018), Developing Schools as Learning Organisations in Wales, Implementing Education Policies, OECD Publishing, Paris, https://dx.doi.org/10.1787/9789264307193-en.

OECD (2013), Synergies for Better Learning: An International Perspective on Evaluation and Assessment, OECD Reviews of Evaluation and Assessment in Education, OECD Publishing, Paris, https://dx.doi.org/10.1787/9789264190658-en.

Révai, N. (2018), What difference do standars make to education teachers? A review with case studies on Australia, Estonia and Singapore, OECD Publishing Paris, https://doi.org/10.1787/f1cb24d5-en.

Schildkamp, K. (2019), "Data-based decision-making for school improvement: Research insights and gaps", Educational Research, Vol. 61/3, pp. 257-273, http://dx.doi.org/10.1080/00131881.2019.1625716.

Sinnema, C. and L. Stoll (2020), "Learning for and realising curriculum aspirations through schools as learning organisations", European Journal of Education, Vol. 55/1, pp. 9-23, http://dx.doi.org/10.1111/ejed.12381.

Sparks, D. (2004), "Focusing staff development on improving the learning of all students", in Cawalti, G. (ed.), Handbook of Research on Improving Student Achievement, Educational Research Service.

Stoll, L. et al. (2017), "Teacher leadership within and across professional learning communities", in Harris, A., M. Jones and J. Huffman (eds.), Teachers Leading Educational Reform, Routledge, London, http://dx.doi.org/10.4324/9781315630724-5.

Timperley, H., L. Kaser and J. Halbert (2014), "A Framework for transforming learning in schools : innovation and the spiral of inquiry", Seminar series, No. 234, Centre for Strategic Education.

Timperley, H. and J. Parr (2009), "Chain of influence from policy to practice in the New Zealand literacy strategy", Research Papers in Education, Vol. 24/2, pp. 135-154, http://dx.doi.org/10.1080/02671520902867077.

Timperley, H. and J. Parr (2009), "What is this lesson about? Instructional processes and student understandings in writing classrooms", Curriculum Journal, Vol. 20/1, pp. 43-60, http://dx.doi.org/10.1080/09585170902763999.

Timperley, H. et al. (2007), Teacher Professional Learning and Development Best Evidence Synthesis Iteration [BES], Ministry of Education, Wellington, http://educationcounts.edcentre.govt.nz/goto/BES (accessed on 11 February 2021).

Victoria State Government (2020), Implementing FISO through professional learning communities, https://www.education.vic.gov.au/school/teachers/management/improvement/plc/Pages/plcguide.aspx (accessed on 18 February 2021).

Victoria State Government (2020), Professional practice days, Victoria State Government - Education and Training, https://www.education.vic.gov.au/school/teachers/teachingresources/practice/improve/Pages/ppepractice-days.aspx (accessed on 15 April 2021). 
Welsh Government (2020), Curriculum for Wales guidance, Education Wales, Cardiff.

Welsh Government (2020), Education in Wales: Our national mission - Update October 2020, Welsh Government, Cardiff, https://gov.wales/sites/default/files/publications/2020-10/education-in-Walesour-national-mission-update-october-2020.pdf.

Welsh Government (2020), National Approach to Professional Learning - High-level summary, https://hwb.gov.wales/professional-development/national-approach-to-professional-learning (accessed on 13 January 2021).

Welsh Government (2020), National School Categorisation System A guide for parents and carers, Welsh Government, Cardiff, https://gov.wales/sites/default/files/publications/2020-01/national-schoolcategorisation-system-guidance-for-parents-and-carers-2.pdf (accessed on 12 February 2021).

Welsh Government (2020), Schools as learning organisations - Hwb, https://hwb.gov.wales/professionaldevelopment/schools-as-learning-organisations (accessed on 11 February 2021).

Welsh Government (2019), Draft evaluation and improvement (accountability) arrangements for Wales, http://www.gov.wales/educationandskills (accessed on 25 January 2021).

Welsh Government (2019), Professional standards for teaching and leadership, Welsh Government, Cardiff, https://hwb.gov.wales/api/storage/19bc948b-8a3f-41e0-944a-7bf2cadf7d18/professionalstandards-for-teaching-and-leadership-interactive-pdf-for-pc.pdf (accessed on 12 February 2021).

Welsh Government (2018), Schools as learning organisations - Case Studies, Hwb website, https://hwb.gov.wales/professional-development/schools-as-learning-organisations\#case-studies (accessed on 25 February 2021).

Welsh Government (n.d.), National pedagogy project - Hwb, https://hwb.gov.wales/professionaldevelopment/national-pedagogy-project (accessed on 25 February 2021). 


\section{Teachers' Professional Learning Study}

This report is part of the OECD Teachers' Professional Learning (TPL) Study.

The TPL study examines the policy environments that support teachers'

professional growth by exploring common strengths and challenges in

participating jurisdictions. In doing so, the TPL study aims to facilitate peer

learning, enrich national debates through international exchange and support

the development of effective teacher learning systems at both the system and school levels.

For more information

Contact: Deborah Nusche, project leader, Deborah.Nusche@oecd.org

This work is published under the responsibility of the Secretary-General of the OECD. The opinions expressed and arguments employed herein do not necessarily reflect the official views of OECD member countries.

This document, as well as any data and any map included herein, are without prejudice to the status of or sovereignty over any territory, to the delimitation of international frontiers and boundaries and to the name of any territory, city or area.

The statistical data for Israel are supplied by and are under the responsibility of the relevant Israeli authorities. The use of such data by the OECD is without prejudice to the status of the Golan Heights, East Jerusalem and Israeli settlements in the West Bank under the terms of international law.

The use of this work, whether digital or print, is governed by the Terms and Conditions to be found at http://www.oecd.org/termsandconditions. 